\title{
DE LA MUERTE DE TARTESOS. EVIDENCIAS EN EL REGISTRO POBLACIONAL
}

\author{
ON THE DEATH OF TARTESSOS. THE SETTLEMENT EVIDENCE
}

\author{
por \\ JOSÉ LUIS ESCACENA CARRASCO
}

\begin{abstract}
RESUMEN: Cuando se lleva a cabo la comparación de las estratigrafías obtenidas en los yacimientos protohistóricos de Andalucía occidental, se observa una grave crisis poblacional que coincide básicamente con el final del mundo tartesio. Se pretende en el presente artículo registrar documentalmente dicho problema, a la vez que precisar su datación. Se señalan además las diferencias con que esta situación crítica afectó a unas comarcas y a otras.
\end{abstract}

\begin{abstract}
The comparative study of a serie of estratigraphic sequences of western Andalusia shows that the crisis that leads to the Tartesos death left clear tracks in the old human occupation. This work intends to relate these evidences and to concrete, as much as possible, the chronology of the critical period and the differences that this stage caused in various regions.
\end{abstract}

\section{CONSIDERACIONES INICIALES}

El presente artículo forma parte de una serie de trabajos en los que venimos abordando junto a otros colegas algunos de los problemas históricos que la investigación tiene planteados hoy acerca de la Protohistoria de la Baja Andalucía (Belén y Escacena e.p.a. Idem e.p.b. Belén y otros 1991. Escacena y Belén e.p.). Se pretende en él, en concreto, analizar la documentación arqueológica disponible para el estudio del final de una etapa que viene llamándose tradicionalmente «mundo tartesio colonial», pero también «Hierro Antiguo»y «Periodo Orientalizante» del Guadalquivir inferior. Este estudio completa a nuestro entender otro ya publicado en el que se abordaron los aspectos concernientes al momento inaugural del poblamiento propiamente tartesio (Escacena y Belén 1991). Su objetivo es pues, como aquél, recopilar las evidencias estratigráficas de los poblados protohistóricos de Andalucía occidental que hablen, ahora, de la fase orientalizante en sus momentos finales, tenida como la etapa de transformación de Tartesos en algo diferente de lo que antes había sido. 
No es nuestra intención tratar aquí en profundidad, a pesar de lo que los textos escritos antiguos puedan afirmar sobre los límites geopolíticos de este mundo hasta Mastia al menos (Av. Or. Mar. 462-463), los yacimientos de Andalucía oriental y del Sureste ibérico, si bien unas cuantas referencias -de las que no nos privaremos al final de nuestro estudio- a lo que en algunos de esos territorios ocurre, puede arrojar cierta luz para la solución de muchos problemas de la Protohistoria meridional; igual que ayuda sobremanera y en la misma dirección el análisis de la ocupación orientalizante de ciertas áreas extremeñas (Bendala 1990).

El país tartesio se configura, a partir sobre todo del Bronce final precolonial, como una unidad cultural que tiene uno de sus pilares fundamentales en el elevado índice demográfico deducido de la enorme cantidad de yacimientos constatados, y que se sustenta a su vez en una geografía con tres unidades morfológicas principales: $\boldsymbol{a}$ ) la depresión inferior del Guadalquivir, que ocupa la parte central de la región desde las campiñas bajas cordobesas hasta el Océano; y dos grupos de cuencas secundarias que la jalonan al este y al oeste, a saber: $\boldsymbol{b}$ ) las tierras regadas por el Barbate y el Guadalete en la provincia de Cádiz; y c) las que drenan el Tinto, el Odiel, el Piedras y el Guadiana en la de Huelva. Esa es la gran comarca que trataremos, a la que sirve de límite septentrional Sierra Morena y de fronteras naturales oriental y occidental las estribaciones montañosas de la Subbética y el Guadiana respectivamente (Díaz del Olmo 1989. Mayoral 1989. Rubio 1989). La inclusión aquí de yacimientos que no pertenecen al Bajo Guadalquivir propiamente dicho, como el LLanete de los Moros de Montoro por ejemplo, queda justificada en las estrechas semejanzas que las tierras de la cuenca media del río a su paso por la provincia de Córdoba presentan con las campiñas sevillanas, haciendo de aquellas comarcas una mera prolongación del mundo tartesio según se ha demostrado recientemente (Murillo 1991: 731-745). En cambio, si los Turdetanos fueron los herederos directos de las poblaciones locales tartesias (Escacena 1989), es suficiente el testimonio de Estrabón (III,2,1) para considerar el Guadiana la frontera occidental, y excluir por tanto del presente estudio los núcleos de habitación portugueses -en el Hierro Antiguo territorio de los Coniosa pesar de los empeños en contra de alguna obra reciente (Judice 1988); y por supuesto los de Extremadura. La exclusión del área lusitana parte además de nuestra adhesión a la hipótesis que otorga una datación relativamente tardía a muchas de las estelas epigráficas encontradas en dicho territorio (De Hoz 1989: 527. Maluquer 1968: 99), de manera que la lengua que su escritura contiene y los hablantes que la usaron se fecharían en gran parte durante la segunda Edad del Hierro o al menos a partir del siglo VI a.C., y no exclusivamente en época orientalizante.

Fue sin duda el auge demográfico rastreable desde el siglo IX a.C. (Escacena y Belén 1991) lo que dotó a este triángulo que hemos acotado de las bases suficientes para sostener una cultura que, a pesar de presentar puntos de marcado contraste con su hinterland -caso de Cádiz, por ejemplo, debido a su carácter colonial-, ofrece la suficiente homogeneidad como para pensar que en todas sus comarcas se desarrollaron al unísono unos mismos repertorios de manifestaciones ergológicas. La aceptación de esta premisa ha presidido varios de los trabajos que sobre este mundo hemos desarrollado recientemente (Belén y Escacena e.p.a. Escacena y Belén 1991: 11), y viene a admitir básicamente que las similitudes en las colecciones de artefactos obtenidas en los distintos yacimientos constituyen un índice evidente de coetaneidad. Es posible aceptar, en este sentido, que determinados objetos aislados puedan responder a comportamientos cronológicos dispares entre unos lugares y otros; pero nos parece más improbable que conjuntos completos de igual contenido muestren fuertes tendencias a aparecer en fechas distintas en zonas tan próximas entre sí y tan bien comunicadas, y a la vez geográficamente tan semejantes, como las campiñas del sur de Córdoba y del norte de Sevilla por ejemplo. Somos conscientes de que estos presupuestos teóricos y metodológicos implican de alguna forma una «negación de las singularidades», de forma que pueden otorgar un barniz de homogeneidad a un panorama que pudo ser en la realidad más diverso de lo que a simple vista aparece ante nuestros ojos. Este peligro que nosotros hoy corremos y asumimos se ha intentado 
evitar, de hecho, depositando con frecuencia una fe ciega en los análisis radiocarbónicos, religión que no profesamos, y sería mucho menor si contáramos con estudios tipológicos y ẹtratigráficos más abundantes y precisos. Pero, en el estado actual de la investigación, ni lo uno ni lo otro de forma separada parecen todavía pilares seguros en los que sostener el estudio de la época que aquí se trata. Es más, el carácter artesanal y hasta doméstico que presidió la fabricación muchos de los objetos que nos han llegado de los pueblos protohistóricos de Andalucía recomienda no tenerlos de forma aislada por marcadores cronológicos de excesiva precisión, sino usarlos como tales sólo formando parte de conjuntos más complejos. Unicamente las manufacturas importadas resisten de algún modo una consideración excepcional a esta norma, como ocurre por ejemplo con la cerámica griega.

Teniendo por base para nuestro análisis las consideraciones hasta ahora expuestas, resulta clarificador para entender el final de la etapa tartesia hacer un recorrido por sus yacimientos más profundamente estudiados. Se observará que este paseo viene a demostrar que en el registro estratigráfico de muchos hábitats quedó marcada la huella de una profunda crisis, que afectó en mayor o menor medida a casi todos los rincones del país. Además, cuando estas evidencias se plasman sobre el mapa y sobre las características geográficas de cada comarca, empiezan a comprenderse ciertos matices que individualizan sectores donde la etapa crítica afectó con distinta intensidad, de forma que es posible empezar a rastrear la impronta arqueológica de algunas de las muchas razones que se conjugaron a lo largo del siglo VI a.C., pero sobre todo durante su segunda mitad, para dar al traste con el floreciente mundo orientalizante de la Baja Andalucía. En cualquier caso, parece evidente que la investigación de todas estas cuestiones debe prescindir de momento de aquellos sitios no excavados y sólo conocidos por prospecciones superficiales, ya que la información de ellos deducida resulta demasiado imprecisa.

Por exponer en cierto orden los datos disponibles, el itinerario propuesto puede empezar, por ejemplo, en la provincia de Córdoba, para, siguiendo una dirección aproximada norte-sur, acabar en las costas atlánticas de la Bahía de Cádiz, donde las poblaciones orientales de la propia Gadir y del Castillo de Doña Blanca constituyeron sin duda una de las claves explicativas del profundo cambio histórico que marcaría en Andalucía occidental el comienzo de la etapa orientalizante y la herencia de ésta en el posterior mundo turdetano (Ruiz Mata 1987a).

\section{ANÁLISIS DE LOS ASENTAMIENTOS}

\section{1.- Montoro}

Las secuencias estratigráficas hasta ahora publicadas del Llanete de los Moros de Montoro, en la provincia de Córdoba (Martín De La Cruz 1985 y 1987), han sido objeto por nuestra parte de una revisión que afecta a su fase del Bronce final (Escacena y Belén 1991: 11-12). Si las discrepancias con el excavador fueron entonces importantes, en lo relativo a la fase orientalizante coincidimos con él en la valoración de los datos y de la estratigrafía.

En síntesis, en este yacimiento se producen, como en muchos otros, cambios importantes durante el siglo VI a.C. Estos se constatan sobre todo en los estratos VI-IX, fechados entre el 575 y el 450 a.C. y calificados culturalmente como «Hierro Segundo I» o «Ibérico Antiguo». Los problemas parecen allí rastreables desde tiempos anteriores, porque existe un hiato ya a comienzos del Hierro Antiguo, con un corte en la estratigrafía que el autor calibra en un siglo o poco más de duración, y que sería el responsable fundamental de la escasez de cerámicas grises. Unos sondeos practicados en otros puntos del cabezo han sugerido al excavador que las causas que motivaron el abandono de este sector no fueron las mismas que 
produjeron el despoblamiento de otros yacimientos del Bajo Guadalquivir, citándose en concreto el de Setefilla, sino razones de índole más particular -sin que se digan cuáles-, que llevaron a la población a establecerse en las proximidades, donde la ocupación continúa hasta época romana (Martín De La Cruz 1987: 206-207). Pero, como más adelante veremos, un fenómeno estratigráfico parecido que ocurre en Ategua y Montemolín por ejemplo, sugiere la posibilidad de hallarnos ante grandes asentamientos de la fase orientalizante que reducen drásticamente su extensión a partir del siglo $\mathrm{V}$ a.C.

\section{2.- Ategua}

En el castillo de Teba (Córdoba), A. Blanco (1983: 115-129) obtuvo dos secuencias estratigráficas en los denominados cortes I y II.

La cata I abarca una secuencia ininterrumpida del poblamiento, pues profundizó hasta la tierra virgen. Se practicó en un lugar céntrico del yacimiento, en la zona de la acrópolis en concreto. Aquí el hábitat se inicia en el estrato 13-14, o inferior, con una cronología imprecisa de finales de la Edad del Bronce que la presencia de algún testimonio de cerámica a torno permite fechar en la segunda mitad del siglo VIII o en los inicios del VII a.C. (Blanco 1983: 123-125 y fig. 13:8). Los estratos 11-12 van tal vez al resto del siglo VII a.C. por la datación atribuida a una urna del tipo de las de la Cruz del Negro presente en estos niveles (Blanco 1983: 123). El estrato 10, inmediatamente superior, puede ser datado, gracias a un fragmento de taza esquifoide ática de principios del siglo VI a.C. (Blanco 1983: 120 y fig. 12:2), durante toda la primera mitad de esa centuria. El nivel 9 presenta materiales de cronologías no muy precisas pero que el excavador comparó en líneas generales con la vajilla obtenida en el estrato 10 de la Colina de los Quemados (Blanco 1983: 119, fig: 11:4-16), por lo que no vendría mal asignarle una fecha en torno a la segunda mitad del siglo VI a.C.; porque realmente ambos conjuntos de materiales presentan estrechas semejanzas en sus formas, tratamientos y decoraciones, abundando los cuencos con silueta de casquete esférico que llevan una banda de pintura roja junto al borde como decoración interna, y en los que sólo se ha insunuado el engrosamiento del labio si es que no lo han perdido por completo. El nivel 6-7-8 representa una acumulación de materiales producida durante largo tiempo, y para la cual la excavación proporcionó suficientes elementos cronológicos: hacia el 400 a.C. pueden ser fechados unos vidrios púnicos, y en el 375 a.C. un fragmento de kylix de figuras rojas, elementos que marcarían así el inicio del nivel (Blanco 1983: 116-1 19 y figs. 9:6 y 10:2), de manera que parece faltar en la secuencia todo el siglo $\mathrm{V}$ a.C., al menos en este sector del poblado. La estratigrafía continúa aquí hasta el siglo I a.C. al menos, pero dichas capas más superficiales escapan a las cronologías que queremos abordar en el presente artículo.

El corte II se llevó a cabo en uno de los flancos del asentamiento, y dio con una tosca muralla de mampostería y tierra (Blanco 1983: 125 y fig.14). En él se detectaron niveles arqueológicos pertenecientes sólo a momentos orientalizantes, faltando por completo los de la segunda Edad del Hierro y los de época romana. Aquí se inicia el poblamiento a la vez que en la cuadrícula I, con cerámica a mano de tradición del Bronce final, en el estrato 8, para el que se ofrece datación absoluta por parte del excavador (Blanco 1983: 126), pero al que sería aplicable el siglo VIII a.C. en sus años finales. La presencia de vasijas a torno pintadas en los estratos 6 y 7 fecha el horizonte que les corresponde hacia el siglo VII a.C., tal vez en su primera mitad por los escasos que son aún esos testimonios indicativos del impacto oriental (Blanco 1983: 126 y fig. 13: 22-28). Los posteriores niveles de habitación vienen definidos por los estratos 5, 4 y 3 dentro de los de cronología clara, pues el 2 y el 1 estaban revueltos. Sus dataciones corresponden más o menos a la centuria comprendida entre el 650 y el 550 a.C. a juzgar por los materiales hallados (Blanco 1983: 125126 y fig. 13:9-21). En todo caso, la ausencia total de cerámica griega en los niveles superiores de este sondeo parece indicar que nunca existió poblamiento en el área a partir de la segunda mitad del siglo V a.C. si no antes. 
Posteriores excavaciones realizadas en Ategua sólo han sido publicadas escuetamente, sin que sirvan para el presente estudio por haber afectado principalmente a niveles romanos y medievales del yacimiento, si bien amplían la vida inicial del asentamiento hasta el Calcolítico. De estos otros trabajos sólo merecería recordarse ahora que, en la secuencia estratigráfica obtenida junto a una torre de la muralla meridional, los edificios romanos se superponen directamente a niveles de los siglos VI-V a.C. (Martín-Bueno 1983), lo que sugiere que aquí acabó también la ocupación a finales de la fase orientalizante o muy poco tiempo después.

En resumen, los datos extraidos hasta ahora de Ategua hablan de un poblado de fundación prehistórica que, con algunos vacíos en su ocupación, duró hasta época medieval. Para lo que ahora nos interesa, resulta especialmente interesante la constatación de una reducción del perímetro ocupado por el hábitat a fines del siglo VI a.C., circunstancia que se deduce de la continuidad estratigráfica hasta tiempos romanos y medievales en los sondeos centrales del yacimiento, es decir, en el sector denominado «acrópolis», y de la discontinuidad correspondiente a partir de finales de época tartesia en las catas situadas en la periferia: la II de Blanco y la de la Torre Sur de Martín-Bueno.

\section{3.- Colina de los Quemados}

La estratigrafía obtenida en este yacimiento de la capital cordobesa es fundamental para proporcionar un entramado cronológico a gran parte de la Protohistoria del valle del Guadalquivir. A pesar de que se llevó a cabo en 1966, cuando aún se conocían pocos datos de las Edades del Bronce y del Hierro en Andalucía, los resultados obtenidos y la secuencia estratigráfica y temporal allí establecida continúan hoy plenamente vigentes, sin que se hayan apuntado siquiera unas mínimas correcciones posteriores a las directrices marcadas por sus excavadores. Sólo en momentos más recientes se ha apuntado una nueva fecha para el estrato 12 (Roos 1982: 48) con base en la estratigrafía granadina de Pinos Puente (Mendoza y otros 1981), según la cual dicho nivel del yacimiento cordobés habría que remontarlo al siglo VIII a.C., sobre todo por la presencia de cerámicas a mano pintadas en blanco. Pero casi todas las estratigrafías andaluzas llevadas a cabo con posterioridad a la de Córdoba han usado ésta como guía por su indudable coherencia interna.

La excavación no proporcionó en realidad muchos materiales de cronologías bien conocidas por entonces, como pudieran ser por ejemplo los vasos griegos.

Según los autores, en el nivel 12 se aprecia el impacto de la colonización fenicia, en unos momentos que sitúan hacia el 700 a.C. A partir del nivel 8 aparece en la Colina de los Quemados la cerámica ática, pudiéndose fechar los estratos 8-7 a finales del siglo V y/o a principios del IV a.C., aunque los excavadores piensan sólo en esta última centuria (Luzón y Ruiz Mata 1973: 34-35). La ausencia de barros campanienses, y en general de materiales romanos, supone un terminus ante quem para los estratos finales de la fase prerromana del yacimiento, cuyo análisis no abordaremos por sobrepasar la cronología de los problemas que ahora nos importan. Por otra parte, y en relación a la constatación o no en Córdoba de testimonios posibles de una etapa crítica al final del periodo tartesio, debe traerse a colación la existencia en el estrato 9 de una gruesa capa de incendio que marca la «transición entre lo ibérico y lo orientalizante» (Luzón y Ruiz Mata 1973: 8) y que, si bien los autores interpretan como los restos de un hogar, en otras ocasiones se ha relacionado con algún tipo de conflictos internos (Blanco 1983: 120).

Otros trabajos arqueológicos practicados en este asentamiento antes y después del ya analizado no modifican sustancialmente los datos sobre la ocupación del sitio en época protohistórica (Bernier y Fortea 1963). No obstante, podría añadirse que algunos datos obtenidos a cerca de un kilómetro de distancia de la excavación que acabamos de analizar, sugieren que la mayor extensión del poblado antiguo asentado 
sobre la colina se produjo en tiempos tartesios, ya que sobre estratos de esta fecha se superponen niveles medievales (Marcos 1976-78: 420).

De los datos obtenidos en los Quemados podría sospecharse, como lo hizo Blanco, que el tránsito entre el Hierro Antiguo y el Reciente no se produjo en Córdoba sin traumas. El hecho de que el sitio quedara abandonado al parecer en torno a la segunda mitad del siglo IV a.C., cronología ya matizada en anteriores trabajos (Escacena 1987a: 293 y 1989: 449) y que ha sido aceptada en estudios recientes (Murillo 1991: 472), puede significar que la muerte de Tartesos iniciada dos centurias antes sólo quedó superada temporalmente. Aunque doscientos años de pervivencia puedan parecer muchos para pensar en un abandono del hábitat originado en aquella crisis, la documentación disponible no permite de momento sostener, como nosotros mismos hemos propuesto en otra ocasión (Escacena 1989: 449), que la continuidad entre la Córdoba prerromana y la posterior se produjera a raíz de un desplazamiento del hábitat anterior a la zona romana de la ciudad, pues los testimonios de cerámica de estilo ibérico encontrados en la fundación de Marcelo deben de pertenecer con toda probabilidad a tiempos romanos (García Y Bellido 1970: 8 ss. y fig. 7. Marcos 1976-78: 416)

\section{4.- Setefilla}

Para fechar el emplazamiento de la Mesa de Setefilla, en Lora del Río (Sevilla), se observan ciertas discrepancias entre los propios excavadores, que se manifiestan sobre todo en las últimas etapas de la vida de su fase protohistórica. Esas diferencias, constatadas especialmente cuando algunos de sus materiales han sido publidados de forma separada por distintos autores (Aubet 1982. Escacena 1979-80), quedan desde luego parcialmente desdibujadas en la memoria de excavación que hasta ahora ha visto la luz, la del corte 3 (Aubet y otros 1983). El problema tiene como punto de arranque la dificultad de fechar con precisión los documentos de la fase final del poblado, unas veces por la carencia de elementos realmente útiles para ello y otras a causa de los revoltijos estratigráficos producidos con posterioridad a la ocupación antigua del tell. De ahí que se haya buscado cierto apoyo en pruebas radiocarbónicas (Aubet y otros 1983: 90).

El cabezo de Setefilla tiene en la parte superior de su secuencia un conjunto de niveles medievales desde los que se destruyeron en parte capas protohistóricas; a pesar de lo cual, el nivel prerromano más reciente, el III, tampoco conservado por completo, puede recibir una cronología del siglo V a.C. El hecho de que existan en él algunos fragmentos de cerámica ática de barniz negro -tal vez de fines del siglo $\mathrm{V}$ o de comienzos del IV a.C.- sólo en las fosas medievales-, indicaría que las capas correspondientes a esas fechas podrían estar destruidas (Aubet 1982: 215). En consecuencia, contando con este dato como fecha ante quem para la fase final del corte 3, podría llevarse el estrato III a fines del siglo V a.C., y el IV a comienzos del mismo, lo que parece concordar con gran parte del material turdetano en ellos aparecido (Aubet y otros 1983: 107-117). De más difícil asignación cronológica resultan otros elementos presentes en la fase $\mathrm{V}$, porque tradicionalmente se han venido asignando a dataciones anteriores al siglo $\mathrm{V}$ a.C., como ocurre por ejemplo con las cerámicas pintadas con temas figurativos o decoradas con motivos bruñidos, que, dado lo reducido del área excavada y lo relativamente abundantes que resultan, parecen imposibles de catalogar como arcaismos conservados en todo el poblado o como simples intrusiones de materiales más antiguos en estratos posteriores (Escacena 1979-80: figs. 7, 8:217 y 10:616, 664, 684, 696 y 699).

La fase IV incluye los estratos Vb, Va y VI, con una fecha estimada en torno a la segunda mitad del siglo VI a.C. (Aubet y otros 1983: 101-107). Culturalmente representa un horizonte de transición entre el Orientalizante final y el comienzo de la segunda Edad del Hierro. Sus materiales son en gran medida semejantes a los del estrato 3 del corte abierto en Carmona por Carriazo y Raddatz (1960: figs. 5-10), cuya 
datación final puede fijarse, según más adelante veremos, en los últimos momentos del siglo VI a.C. más o menos.

Para la fase III, definida como orientalizante, se ha dado una fecha central de comienzos del siglo VI a.C., porque sus elementos característicos se asemejan en parte a los ajuares de algunas tumbas de la necrópolis de este mismo yacimiento, en especial a los del túmulo B, y porque así lo certifica el C-14, que ha entregado para el estrato IX, el segundo según se fueron sedimentando los que incluye esta fase, una cifra de $540 \pm 90$ a.C. (Aubet y otros 1983: 90 . Aubet 1982: 215 ). Tal vez el estrato $X$ deba introducirse ya en pleno siglo VII a.C., pues la urna de boca acampanada $\mathrm{n}^{\circ} 161$ (Aubet y otros 1983: fig. 31), y otros materiales que la acompañan como los cuencos con asas de espuerta, van asociados en el túmulo A de su propia necrópolis a fíbulas de doble resorte y a broches de cinturón que parecen requerir esa cronología (Aubet 1975: figs. 13, 23, 35, 40, etc.); y todo ese repertorio de objetos aparece acompañado, en las sepulturas 17 y 30 del mencionado túmulo, de copas y cuencos a torno pintados que tienen claros paralelos en Oriente en los siglos VIII-VII a.C. y aún antes (Salles 1980: 42 ss., lám. 17:26, 28 y ss.). El estrato IX acusa en Setefilla, tal vez en la primera mitad del siglo VII a.C., los primeros y tímidos influjos de la aculturación oriental (Aubet y otros 1983: 86-88, fig. 32:155), pero su análisis rebasa el interés que nos lleva a escribir estas páginas.

Recientemente ha sido publicado también el corte 1, practicado en este caso en el extremo oriental del tell (Aubet 1989). La interpretación dada por la excavadora a esta secuencia no hace más que corroborar los datos y las características sobre la ocupación ya analizadas, volviendo a sugerir una etapa crítica en el poblado en torno al 500 a.C. o a comienzos del siglo V en líneas generales (Aubet 1989: 308).

En resumen, puede afirmarse que Setefilla conoció en época orientalizante uno de los mayores auges poblacionales de su historia. De hecho, tanto el corte $\mathrm{D}$, realizado casi en el centro de la Mesa (Aubet y otros 1983: 128-131), como hallazgos esporádicos procedentes de la fachada meridional del santuario actual (Ladrón De Guevara y otros 1992) revelan que desde el Bronce Final hasta el siglo VI a.C. estuvo habitada prácticamente toda la meseta, y no sólo el cabezo de su parte norte que hoy sirve de soporte al castillo medieval.

\section{5.- Alhonoz}

Nos interesan de este yacimiento situado en Herrera (Sevilla) principalmente dos secuencias estratigráficas correspondientes a sendas campañas de excavación llevadas a cabo en 1977 y 1978. Con los resultados obtenidos hasta esta última fecha el excavador ha establecido una serie de fases que abarcan la totalidad del poblamiento, desde el Bronce Final a la Romanización (López Palomo 1981: 169-171).

Aunque en otro lugar hemos dedicado unas reflexiones al horizonte fundacional del poblado (Escacena y Belén 1991: 15-16), nuestra atención se centra ahora a partir de la fase II, detectada en los estratos IXVIII de 1977 y IV-III de 1978. Por lo que se refiere a materiales de asignación cronológica relativamente precisa, debe subrayarse que este momento conoce en Alhonoz cuencos de cerámica a mano con el borde engrosado hacia el interior, vasijas de cuerpo esférico y rugoso con el fondo plano, a veces decoradas con impresiones digitales o motivos incisos, platos de barniz rojo y cuencos en forma de casquete esférico en barro gris (López Palomo 1981: figs. 38-40), conjunto que representa la vajilla característica de las poblaciones tartesias durante el siglo VII a.C. En consecuencia, creemos oportuno rebajar en cien años aproximadamente la cronología del siglo VIII a.C. propuesta por López Palomo para este horizonte de Alhonoz, sobre todo porque una modificación en el mismo sentido conviene a la etapa inaugural del hábitat (Escacena y Belén 1991: 15-16).

La fase III abarca grandes paquetes de estratos en la campaña de 1977 (estratos VII-VI-V) y el II de 
1978. Los niveles más profundos de este conjunto llevan cerámicas bícromas que podrían pertenecer a fines del siglo VII o al VI a.C.; y más o menos a la mitad de esta fase los platos de cerámica gris a torno llevan el borde bien indicado mediante un engrosamiento interno, característica que parece muy propia del siglo VI o comienzos del V a.C. en Andalucía occidental, sobre todo si atendemos por ejemplo a los paralelos de las fases IV y V de Setefilla, datada en el Orientalizante final e inicios del Hierro II (Aubet y otros 1983: 101-117), o a las piezas de los niveles 20-18 del Macareno, de similar cronología (Pellicer y otros 1983: 155-157).

Atendiendo a los documentos publicados, hay que pensar en la posibilidad de que en el sector hasta ahora excavado de Alhonoz falten niveles de los siglos V y IV a.C., al menos los correspondientes a los años comprendidos entre el 450 y el 350 a.C. aproximadamente. De hecho, ningún material prerromano tiene por necesidad una cronología exclusiva de esa etapa, y resulta extraña, por otra parte, la ausencia total de cerámica griega de época clásica, que por estas fechas estaba inundando literalmente los territorios andaluces. Por tales razones, es probable que hasta la segunda mitad del siglo IV a.C. no se reinicie la ocupación de Alhonoz, para conocer ahora un auge importante que durará hasta los comienzos de la Romanización.

\section{6.- Carmona}

La estratigrafía realizada en Carmona por Carriazo y Raddatz (1960) ha sido revisada frecuentemente desde pocos años después de su publicación.

En el simposio sobre Tartesos celebrado en Jerez de la Frontera en 1968, E. Cuadrado y M. Pellicer propusieron ya sendas correcciones. Según el primer autor, las cerámicas de barniz rojo andaluzas permiten llevar los estratos 1 y 2 , que los excavadores databan en época romana, a los siglos IV y III a.C., mientras que la capa 4 iría a los siglos VI-V a.C. (Cuadrado 1969: 280-282), en vez de sólo al V como habían querido Raddatz y Carriazo. M. Pellicer aplicó por su parte al estrato inferior una datación de fines del siglo VIII y de comienzos del VII a.C., mientras que el 4 correspondería a los siglos VII-VI a.C. y el 3 a las dos centurias siguientes, quedando así interrumpida la estratigrafía en pleno Hierro Reciente (Pellicer 1969: 300).

Con estas matizaciones, sumadas a otros nuevos cambios propuestos por Arribas y Arteaga, se contó para fechar los materiales y fases de Guadalhorce, de manera que el estrato 3 de Carmona quedaría ahora en los siglos VI y V a.C. y el 4 en el VII (Arribas y Arteaga 1975: 23), cronología en realidad coincidente con alguna prueba radiocarbónica y con una previa revisión de Schubart (1971: 169. El estrato 3 daba 520 \pm 120 y $450 \pm 50$ ).

Con posterioridad a estas reestructuraciones cronológicas, una nueva propuesta lleva al estrato 5 en torno al 800 a.C., para acabar la secuencia hacia el 400 a.C. aproximadamente (Pellicer 1976-78: 11 ss).

Para abordar el estudio de la cerámica gris de Andalucía, A. Caro (1989: 17) modifica también la datación que los excavadores avanzaron. Parece que esta revisión ha tenido presentes las anteriormente citadas, e incluso otra llevada a las I Jornadas sobre el Mundo Ibérico celebradas en Jaén en 1985 (Escacena 1987a: 283-285); pero en realidad no se ofrece argumento alguno en la que apoyarla, si bien se alude a un previo estudio de estratigrafía comparada no contenido en la obra (Caro 1989: 13). Esta propuesta hace acabar la secuencia de Carriazo y Raddatz a mediados del siglo VI a.C.

A la luz de sondeos estratigráficos más recientes, son posibles hoy mayores precisiones en estos esquemas cronológicos, aunque en gran medida no se puedan modificar sustancialmente las últimas correcciones señaladas. El estrato 5 escapa de alguna forma a nuestro interés ahora, aunque su estudio lo hemos abordado en profundidad en otra ocasión (Escacena y Belén 1991: 16). El 4 ofrece un contexto 
relativamente viejo dentro del horizonte tartesio de la Edad del Hierro, porque, a pesar de caracterizarse sobre todo por la abundancia de cerámicas a mano, existe en él ya algún testimonio a torno que alude a unos primeros contactos con la colonización fenicia. Se trata del hombro de un vaso pintado con un ramiforme (Carriazo y Raddatz 1960: fig. 11:3), que tiene sus paralelos occidentales mejor fechados en el horizonte II del recinto de Tanit en Salambó, donde se documentan hacia el 700 a.C. (Belén y Pereira 1985: 326-327. Harden 1937: 85-89 y fig. 4:1). Respecto a los demás estratos, no contamos realmente con bases cronológicas claras e indiscutibles, aunque tal vez sea posible, en atención a la numerosa presencia de cuencos con el labio engrosado en el estrato 3, llevar dicho nivel hasta el siglo VI a.C. Esta capa finaliza por cierto con un incencio generalizado que provoca el abandono de vasijas enteras. Tales recipientes responden a tipos de cuerpo globular y baquetón en el hombro cuyos comienzos se fechan en el Macareno hacia el 500 a.C. (Pellicer 1982: 400 y fig. 22:3). Los estratos 2 y 1 no llevan materiales necesariamente posteriores al s. V a.C., y tanto los platos de tradición fenicia como los cuencos de borde grueso y las cerámicas decoradas con bandas rojas limitadas por líneas negras recomiendan cronologías altas dentro de la segunda Edad del Hierro, en ningún caso posteriores al siglo V a.C. (Carriazo y Raddatz 1960: figs. 3 y 4), datación que podría apoyarse también, en última instancia, en la ausencia de cerámica griega, de aparición tan frecuente en los yacimientos andaluces que conocieron ocupación a partir de la segunda mitad del siglo $\mathrm{V}$ a.C.

A escasos metros del sondeo de Carriazo y Raddatz, una excavación posterior denominada «corte CA80/A» ha venido a demostrar la conveniencia de todas estas revisiones cronológicas (Pellicer y Amores 1985). Coincidimos básicamente con la interpretación cronoestratigráfica de esta secuencia, por lo que eludimos su tratamiento en profundidad. No obstante, deberíamos recordar al menos los problemas derivados de la dificultad de fechar con precisión los niveles superiores, problemas que tienen su razón de ser en la escasez de cerámica griega, una especie que a los autores les parece «deficientemente representada» (Pellicer y Amores 1985: 167) en la creencia tal vez de que la riqueza arqueológica de Carmona durante los comienzos del Hierro reciente debería ser mayor de lo que los datos reflejan. El nivel de incendio detectado por Raddatz y Carriazo también quedó constatado en esta cata, donde aparece en el estrato IV (Pellicer y Amores 1985: 70). No escapa a los excavadores la sincronía de ambas capas de destrucción por el fuego, que responderían a un mismo episodio de incendio y que, en coherencia con lo defendido por Pellicer en anterior ocasión en que abordó la revisión del sondeo de Raddatz y Carriazo (Pellicer 1969: 300), llevan hasta el siglo V a.C. Pero ya hemos argumentado aquí nuestras razones para retrasar ligeramente la datación de ese contexto. En consecuencia, si dicha unidad sedimentaria quemada corresponde al siglo VI -tal vez en sus momentos finales- más que al V, debería constreñirse la duración calculada para los estratos orientalizantes infrapuestos, pues no parece oportuno, dado el comportamiento general observado en muchos otros yacimientos de la Baja Andalucía (Escacena y Belén 1991), elevar en un siglo todo ese paquete estratigráfico anterior, teniendo así que remontar la cronología de la propia fundación del hábitat.

En Carmona, y en relación con los momentos que aquí nos ocupan, las excavaciones más recientes Ilevadas a cabo que han sido dadas a conocer no reflejan disminución en el tamaño del asentamiento ni discontinuidad poblacional alguna durante los tiempos protohistóricos, pero sí fenómenos importantes de remodelación urbanística que afectaron a la función de algunos de los barrios e incluso a la construcción y utilización de determinados sectores de las estructuras defensivas a partir de la segunda mitad del siglo VI a.C. (Cardenete y otros 1988a: 261-263) y de los inicios del Hierro Reciente (Cardenete y otros 1989: 574).

En síntesis, un repaso crítico a la bibliografía que se ha ocupado de la Carmona pre y protohistórica revela que, tras una fundación calcolítica y unas posteriores ocupaciones de la Edad del Bronce, el mayor 
perímetro corresponde a época tartesia. Durante la segunda mitad del siglo VI se originan modificaciones sustanciales en la organización del hábitat. Tal vez estos cambios hayan quedado parcialmente reflejados en el nivel de incendio detectado en las excavaciones de Raddatz-Carriazo y de Pellicer-Amores, y desde luego condujeron a la reducción del tamaño del hábitat y al desplazamiento de las áreas más ocupadas. De ahí que, frente a la pobre y problemática constatación de niveles turdetanos en el barrio de San Blas (Carriazo y Raddatz 1960. Pellicer y Amores 1985), se observe en otros sectores la superposición directa de estratos prerromanos a los del Bronce Final (Cardenete y otros 1988b: 277-278).

\section{7.- Montemolín}

Los más completos datos estratigráficos publicados hasta la fecha sobre Montemolín, yacimiento situado en las campiñas de Marchena (Sevilla), junto al río Corbones, corresponden a los cortes C y D de las excavaciones practicadas en 1980 (Chaves y De La Bandera 1984), si bien se han llevado a cabo otras campañas posteriores de cuyos resultados se han avanzado algunas noticias (Chaves y De La Bandera 1985 y 1987).

Eludiendo los niveles de habitación prehistóricos, que aquí no importan especialmente, y abordando la estratigrafía desde abajo hacia arriba, el análisis de la secuencia de Montemolín debe comenzar por su estrato II, fechado hacia finales del siglo VIII a.C. y comienzos del VII. Aunque no dio cerámica a torno, determinados fondos planos y otros tantos bordes exvasados parecen responder a las típicas vasijas de cuerpo rugoso esférico y cuello acampanado alisado o bruñido, que imitan la forma del vaso à chardon fenicio (Chaves y De La Bandera 1984: fig. 5.38: a-f y r-s). En consecuencia, no es conveniente fechar esta capa antes de la segunda mitad del siglo VIII a.C.

En su fase 1, el estrato III contenía, como elementos de datación más precisa, un ánfora fenicia que puede pertenecer al siglo VII a.C. aunque el tipo viva en momentos anteriores o posteriores, además de un fragmento a torno pintado con motivos de «molinetes» como los huevos de avestruz de Almuñécar, datados en el siglo VII a.C. (Chaves y De La Bandera 1984: figs. 5.28: b y 5.33. Pellicer 1963: figs. 9 y 18). En su fase más reciente, la 2 , este estrato lleva cerámicas a torno decoradas con temas figurativos entre los que abundan los zoomorfos. Se trata por lo general de grandes pithoi con asas trigeminadas que se disponen alrededor de la boca del recipiente en número de tres o cuatro (Chaves y De La Bandera 1986: 118). Un alabastrón, vasos a mano de tradición indígena y otros productos de alfarería a la rueda completan el repertorio de objetos del estrato, que puede recibir una fecha de la primera mitad del siglo VI a.C., sobre todo atendiendo a la abundancia de cuencos con el borde engrosado hacia el interior, a la presencia de vasos tipo «Cruz del Negro» y al ungüentario de alabastro (Chaves y De La Bandera 1984: figs. 5.8 y 5.19. Mancebo e.p.).

A pesar de que han aparecido en este poblado documentos que pertenecen sin lugar a dudas a la segunda Edad del Hierro, entre los que cabe mencionar monedas hispano-cartaginesas fechadas entre los años 221 y 218 a.C. (Villaronga 1973: 158, clase IX, tipo II) y diversos materiales cerámicos (Chaves y De La Bandera 1984: fig. 5.9:a. García Vargas y otros 1989), parece que Montemolín no conoció poblamiento estable, al menos en el área excavada y dada a aconocer, con posterioridad al siglo VI a.C., fecha a la que se han asignado en gran parte los vasos pintados con temas figurativos de los niveles superficiales del cabezo (Chaves y De La Bandera 1986: 142).

Las cerámicas turdetanas a las que hemos aludido corresponden al estrato IV, el más superficial, que las excavadoras consideran capa revuelta por las labores agrícolas. En realidad, este nivel contiene materiales que en su mayor parte deben fecharse en el Orientalizante final: ánforas fenicias, recipientes decorados con grandes círculos concéntricos en pintura roja, cuencos de fabricación a mano con motivos 
ornamentales consistentes en geometrismos bruñidos, cerámica a torno del tipo «gris de occidente» y vasos de superficies toscas que llevan adornos incisos e impresos (Chaves y De La Bandera 1984: 145-146 y figs. 5.9-5.12). Tal conjunto de formas y de decoraciones conoce sus paralelos más cercanos en el estrato 3 de la excavación de Raddatz y Carriazo en Carmona (1960: figs. 5-10), en el V del corte 3 de la Mesa de Setefilla (Aubet y otros 1983: 101-107, figs. 45 y 46) y en el 10 del sondeo de Luzón y Ruiz Mata en la Colina de los Quemados (Luzón y Ruiz Mata 1973: 24-25 y láms. XXVII-XXXII) entre otros sitios, en los tres casos con una cronología idéntica en torno a las últimas décadas del siglo VI a.C.

De toda esta documentación y de su posición topográfica y estratigráfica en el yacimiento se deduce que, sin imaginar necesariamente un despoblamiento total del asentamiento de Montemolín en tiempos prerromanos, debe admitirse al menos la constatación de importantes cambios en el hábitat desde mediados del siglo VI a.C. y seguramente hasta el final de esa centuria. Esas transformaciones afectaron a una reducción y/o desplazamiento de las áreas ocupadas desde los sectores que habían permanecido habitados desde el Bronce Final hasta tiempos orientalizantes. En esta parte que se abandona se habían asentado ricas estructuras arquitectónicas, algunas de las cuales presentan tan fuertes semejanzas con viviendas siropalestinas, sobre todo en sus técnicas constructivas y en la disposición de sus plantas, que han sido hipotéticamente vinculadas a gentes orientales asentadas en el interior del territorio tartesio (Chaves y De La Bandera 1991: 714), suministrando así un nuevo apoyo material a la colonización agrícola replanteda por C. González Wagner y J. Alvar (1989). Las circunstancias en que se hallaron las construcciones deshabitadas a partir de fines del siglo VI a.C. no revelan huídas precipitadas por incendios fortuitos, de ahí que haya que buscar en otra causa la razón de dicho abandono. En cualquier caso, se sabe al menos que esa zona del poblado llegó a convertirse en un área de expolio por parte de la posterior población turdetana del propio Montemolín o de otros hábitats de los alrededores, porque se han conservado, colmatadas de tierras negruzcas ricas en materia orgánica y de restos arqueológicos postorientalizantes, estructuras que en terminología de E.C. Harris (1991: 93) llamaríamos «elementos interfaciales verticales», y que corresponden a las zanjas abiertas en la superficie del tell para extraer los mampuestos de los antiguos muros y de sus cimientos (Chaves y De La Bandera 1991: 701).

\section{8.- El Macareno}

En el Cerro Macareno (La Rinconada, Sevilla) se han llevado a cabo tres actuaciones arqueológicas (Martín De La Cruz 1976. Fernández Gómez y otros 1979. Pellicer y otros 1983), de las que sólo la primera y la última citadas afectan a niveles de ocupación que cubren el tránsito de la primera a la segunda Edad del Hierro.

En el llamado «Corte F», que consistió en realidad en la limpieza de un talud del yacimiento, el inicio del Hierro Reciente se constata a partir del estrato 5, ya que el 6, situado por debajo de aquél, llevaba materiales que deben corresponder globalmente a una fase tardía del Orientalizante (Martín De La Cruz 1976: 35).

En el sondeo practicado por el equipo de la Universidad de Sevilla dirigido por M. Pellicer, el paso de la fase tartesia a la prerromana se establece en los niveles 18,17 y 16 , el último de los cuales puede considerarse ya del Hierro II.

En ninguna de estas dos excavaciones reseñadas se ha observado hiato poblacional alguno entre el periodo orientalizante y el postartesio, de forma que todos los datos disponibles sugieren que la crisis que venimos constatando en tantos yacimientos no afectó visiblemente al Cerro Macareno, que conoció una ocupación continuada desde el siglo VIII a.C. hasta poco antes del cambio de Era. En tal sentido, y por si algo tiene que ver en esta superación de la situación crítica el privilegiado lugar donde se enclava dicho 
hábitat, debemos recordar que este poblado nació al parecer junto a un meandro del Guadalquivir hoy inexistente (Fernández Gómez y otros 1979: 13. Pellicer y otros 1983: 18), lo que le permitió disponer con toda probabilidad de su correspondiente embarcadero fluvial, sólo abandonado a partir de la variación del curso del Guadalquivir (Corzo 1991: 95. Pellicer y otros 1983: 108).

\section{9-10.- Cerro de la Cabeza-Colina de San Antonio}

Situado unos quinientos metros al norte del anfiteatro de Italica, en el mismo término de Santiponce, el Cerro de la Cabeza ha sido objeto de un sondeo en la corona de la colina que ocupa el tell (Domínguez y otros 1988) tras unas previas prospecciones superficiales (Escacena 1983: 39-83). El problema fundamental que presenta el estudio de este complejo arqueológico, en el que hemos englobado al Cerro de la Cabeza y a la propia ltalica, es que debe ser analizado conjuntamente con los datos aportados por las excavaciones del Pajar de Artillo (Luzón 1973) y de otros puntos del casco viejo de Santiponce situados en el Cerro de San Antonio, a espaldas de la ladera sobre la que descansan las caveae del teatro romano (Pellicer y otros 1982). Además, la visión de ambos sectores debe llevarse a cabo con la previa aceptación de una serie de revisiones sobre la primera cronología propuesta por Luzón para la estratigrafía del Pajar de Artillo en la línea en que ha sido argumentada por nosotros en otras ocasiones (Escacena 1987a: 285288, y 1989: 446-447).

El hecho de que ambos yacimientos se deban considerar el mismo poblado se basa, aparte de en su proximidad, en la coincidencia cronológica entre el final de uno (Cerro de la Cabeza) y el principio del otro (Colina de San Antonio). Argumentamos en otra ocasión (Escacena 1983: 59-60) que esta hipótesis se justificaría en un traslado de población de un cerro a otro cercano motivado tal vez por las variaciones de un meandro del Guadalquivir que correría a sus pies. Tal posibilidad ha sido recogida y completada recientemente por R. Corzo (1991: 94-95), quien sostiene que la actual Rivera de Huelva, afluente del Guadalquivir a estas latitudes por su margen derecha, ha reaprovechado en su trazado esa vieja madre abandonada, cuyo uso en época romana queda certificado por las alfarerías que Bonsor (1989: 82) localizara en sus orillas.

Por otra parte, la revisión de las dataciones que Luzón aplicó a los estratos inferiores de la secuencia del Pajar de Artillo tiene por pilares los datos obtenidos en el sondeo de la Casa de la Venus, donde se obtuvieron niveles fundacionales de la segunda mitad del siglo IV a.C. (Pellicer y otros 1982: 18), así como el estudio en profundidad de las fechas en que se constatan en los más importantes yacimientos localizados hasta hoy en el Bajo Guadalquivir las primeras cerámicas campanienses (Ventura 1985). En cualquier caso, sin argumentar explícitamente los cimientos de sus discrepancias, el estudio del denominado «corte F» del Cerro Macareno partió ya de revisiones sustanciales de la estratigrafía italicense conseguida por Luzón (Martín De La Cruz 1976: 25 y nota 21).

Así pues, puede afirmarse que, después de iniciado el hábitat durante una fase tardía del Bronce Final o incluso en tiempos orientalizantes, el asentamiento no sufrió hiato alguno hasta enlazar con la etapa romana más conocida de Italica. Esta continuidad demuestra que, al igual que el Macareno, también este poblado soslayó la crisis que al final del siglo VI a.C. afectó al mundo tartesio. En esa fecha, el núcleo habitado quedaba restringido al Cerro de la Cabeza, por lo que sólo una excavación en extensión de dicho sector podrá revelar un día si, a pesar de no haber quedado desabitado por completo en esa etapa de recesión, experimentó altibajos en su perímetro urbano.

Con la documentación de que hoy disponemos, no parece que pueda afirmarse que la creación del nuevo núcleo de la Colina de San Antonio se debiera a un auge poblacional generalizado de la comunidad turdetana, que más bien conoció en algunos enclaves nuevos estadios negativos por esos años del siglo IV a.C. (Pellicer 1978: 397. Vera 1987: 56). Pero esos problemas no nos incumben ahora directamente. 


\section{1.- El Carambolo}

Fuera la que fuese la fecha fundacional del poblado del Carambolo, lo cierto es que el estrato III puede ser datado en el siglo VII a.C., sobre todo con base en la cerámica gris (Carriazo 1978: 117), si bien en esta misma capa se han señalado documentos más viejos, en concreto importaciones de cerámica de Samaria (Schubart 1971: 169, nota 7), que deberían considerarse testimonios residuales de la ocupación anterior del sitio.

Tanto El Carambolo Alto como el Bajo pueden tenerse por sectores de un mismo hábitat. Una simple ojeada al terreno demuestra, de hecho, la inexistencia de solución de continuidad entre lo que en principio se nombraron como asentamientos distintos aunque relacionados.

De los datos extraidos por Carriazo parece oportuno deducir que la ocupación de esta colina del borde oriental del Aljarafe se prolongó durante más tiempo en lo que en su día se llamó Carambolo Bajo, una zona que reposa sobre la ladera que se asoma al Guadalquivir. Así, en esta parte inferior se documentan elementos que pueden datarse a fines del siglo VI o, en todo caso, a comienzos del V a.C., como son las grandes fíbulas anulares (Carriazo 1978: 136), con esta cronología en el cercano Cerro Macareno (Pellicer y otros 1983: 154, fig. 56:494).

Las circunstancias que presidieron el hallazgo y posterior excavación del yacimiento del Carambolo impiden hacer muchas más precisiones sobre la ocupación correspondiente a la época que ahora nos importa. En cualquier caso, debe quedar claro al menos que, después del siglo VI a.C. o, como mucho, de comienzos de la centuria siguiente, no existió allí un asentamiento permanente. El hallazgo, pues, de algún objeto aislado cuya tipología parece exigir fechas posteriores, en torno tal vez a los siglos III o II a.C. (Carriazo 1973:360, fig. 482), puede ser interpretado como la huella de visitas esporádicas al lugar durante tiempos prerromanos.

La valoración de este asentamiento humano dentro del problema que ahora abordamos debe tener presente que la misma tesaurización y ocultación de las joyas que han dado fama al sitio presuponen la existencia de un importante momento de peligro, que la posición estratigráfica del conjunto aureo y otras características relativas al recipiente en el que éste se introdujo (Carriazo 1970a: 3-4 y 49-50; y 1973: 125126) llevan, a pesar de su escasa precisión, aproximadamente al siglo VI a.C. Además, si la zona más alta del Carambolo fue un lugar de culto, como se ha llegado a sugerir (Blanco 1979: 95-96), deberíamos concluir que dicha presión violenta se ejerció sobre un centro ceremonial que pudo haber sido en época tartesia un importante núcleo de poder, y que acabaría con un incendio previo a la deposión del tesoro según el informe emitido por Maluquer sobre la estratigrafía (Carriazo 1970a: 49-50. Kukahn y Blanco 1959: 4849).

En los alrededores del Carambolo se conocen poblados que sostuvieron un determinado componente demográfico en época turdetana, e incluso muy anterior a veces. Tanto en el caso de San Juan de Aznalfarache, la antigua Osset (Escacena 1986: 540-541), como en el de Santa Eufemia (Buero y otros 1978. Escacena 1983: 65), los testimonios de la segunda Edad del Hierro corresponden a hallazgos originados en prospecciones superficiales del terreno, y no obtenidos en excavaciones. De ahí la dificultad para usarlos a la hora de valorar, como lo hemos hecho en el caso de Italica, si la crisis observada en El Carambolo implicó o no desplazamientos locales de población. En cualquier caso, la cronología de este abandono, distinta a la del Cerro de la Cabeza de Santiponce, no deja de levantar sospechas que vinculan las causas de la desocupación más a los problemas generales que durante la segunda mitad del siglo VI a.C. afectaron al mundo tartesio que a razones particulares de la comarca donde el poblado se asentó. Y debe recordarse en todo momento que la inexistencia en El Carambolo de cerámica de barniz rojo posterior a los inicios del siglo VI a.C. (Ruiz Mata 1986c: 549-552) puede ponerse en relación con un fenómeno bien 
estudiado recientemente por M.E. Aubet (1987: 247): la desconexión a partir de esta fecha entre las colonias fenicias occidentales y las metrópolis del Mediterráneo oriental tras la caída de Tiro en manos asirias.

\section{2.- Sevilla}

Por lo que a los niveles de ocupación prerromana se refiere, fue F. Collantes de Terán quien obtuvo por primera vez una secuencia estratigráfica en Sevilla, excavación que sólo se daría a conocer de manera escueta con motivo de la publicación de su tesis doctoral (Collantes De Terán 1977: 61-72). Contando con el precedente de una revisión de esta secuencia realizada por Blanco (1979: 91-92), por tres veces hemos tratado ya con relativa profundidad los datos obtenidos en dicho sondeo (Escacena 1987a: 279-280, 1987b: 74-75 y 1989: 443-444). En consecuencia, sólo cabría concluir aquí, para no pecar de reiterativos, la imposibilidad de apreciar a partir de ellos una crisis evidente entre la Hispalis de época tartesia y la prerromana. Debemos señalar, no obstante, que una interpretación de la estratigrafía de este sector sevillano de la Cuesta del Rosario paralela a la nuestra (Vera 1987) discrepa profundamente de las deducciones cronológicas de Blanco y de las que en aquellas ocasiones propusimos, sobre todo con base en el rechazo de la procedencia de los materiales orientalizantes, que el autor excluye de la colección de objetos rescatados en dicha excavación y depositados hoy en el Museo Arqueológico de Sevilla (Vera 1987: 43). Esta posición difiere evidentemente de la sostenida por el propio excavador, quien señaló que en el estrato inferior obtuvo, entre otras cosas, vasijas a mano «con pulimento» y tonos negruzcos, además de recipientes de piedra caliza (Collantes De Terán 1777: 63-64), estos últimos con claros paralelos de época orientalizante en el cercano Carambolo (Carriazo 1973: 293-295, lám. 214). Por lo demás, una lectura minuciosa de esta revisión de M. Vera no aclara, sino todo lo contrario, si dichos testimonios deben excluirse del lote hallado por Collantes de Terán «debido a lo inseguro de su pertenencia a la secuencia estratigráfica de Cuesta del Rosario» (Vera 1987: 43) o si «los materiales de estos primeros niveles pueden considerarse como elementos intrusivos en el yacimiento» (Vera 1987: 45-46), pues para compaginar ambos planteamientos contradictorios sólo se nos ocurre que dicha intrusión se haya producido dentro de los propios almacenes del Museo Arqueológico de Sevilla, donde existe de hecho cierta documentación etiquetada con la probable procedencia de ese punto de la ciudad (Campos y otros 1988: 10).

Más firmes apoyos para el conocimiento de la etapa protohistórica de la ciudad ofrecen otros trabajos arqueológicos recientes, sobre todo los llevados a cabo bajo la dirección de J.M. Campos Carrasco, que han venido a confirmar la fecha tartesia de su fundación como hábitat (Campos 1985. Campos y otros 1988). En ninguno de ellos queda reflejada una crisis perceptible estratigráficamente entre el final de la etapa orientalizante y el comienzo del mundo turdetano de la segunda Edad del Hierroa. Por el contrario, dichas excavaciones han mostrado secuencias deposicionales ininterrumpidas durante toda la vida protohistórica de la ciudad (Campos y otros 1988: 21-22).

\section{3.- El Gandul}

Situado en el extremo meridional de Los Alcores, en el término de Alcalá de Guadaira (Sevilla), la fase protohistórica de este poblado se conoce básicamente por un sondeo estratigráfico (Pellicer y Hurtado 1986) al que precedió una prospección superficial (Amores 1982: 90-91).

La excavación, cuyos resultados han sido publicados de forma escueta aún, ha dado como resultado una secuencia estratigráfica que no se interrumpe en el tránsito de la primera a la segunda Edad del Hierro, momento que debe corresponder al estrato $\mathrm{V}$. Mientras esta cata no se dé a conocer más extensamente 
carecemos de bases suficientes para hacer una lectura ajustada de la misma.

\section{4.- Lebrija}

En 1986 se obtuvo en un solar de la calle Alcazaba de Lebrija, en la falda meridional del Cerro del Castillo, una secuencia estratigráfica que arranca del Epipaleolítico y que, con algunos hiatos, llega hasta la actualidad (Caro y otros 1986).

Los vacíos en la ocupación del promontorio corresponden básicamente a determinados momentos del Calcolítico y de la Edad del Bronce. Para los tiempos protohistóricos no se detecta en el punto excavado ningún indicio que permita sostener un abandono del hábitat entre los siglos VI y V a.C., pero sí un nivel de destrucción que en unas primeras impresiones ha sido relacionado con el final del mundo tartesio (Caro y otros 1986: 173).

En la zona denominada «Huerto Pimentel», A. Tejera practicó unos años antes un sondeo que refleja en cambio una situación diferente. Aquí, en la periferia de lo que podríamos denominar la acrópolis de Nabrissa, la ocupación humana debió quedar truncada tras la fase orientalizante, porque después del estrato II, que puede ser llevado a esa etapa por los materiales que entregó (cerámica de barniz rojo e indígena bruñida entre otros), sólo se acumuló un nivel de la Edad Media que contenía un único fragmento residual de vaso pintado al estilo ibérico (Tejera 1985: 92).

La comparación de los datos obtenidos en el solar de la calle Alcazaba con los aportados por Huerto Pimentel sugiere que entre el periodo tartesio y el prerromano existió en Lebrija una contracción del poblado que originó una reducción notable de su perímetro, quedando éste restringido a la zona más alta y fácil de defender. Parece que este fenómeno no aconteció sin violencias, pues a este momento correspondería la construcción de un foso defensivo (Caro 1986-87: 61).

\section{5.- Asta Regia}

En las memorias de las excavaciones que M. Esteve Guerrero llevó a cabo en Mesas de Asta (Jerez de la Frontera, Cádiz), se señala frecuentemente que el yacimiento presentaba múltiples revoltijos, de forma que no era posible establecer con claridad la secuencia estratigráfica del asentamiento (Esteve 1945, 1950, 1962 y 1969). Sabemos no obstante, gracias al hallazgo de ciertos materiales cerámicos, que el sitio se inauguró como hábitat hacia finales del Neolítico (Esteve 1979: 35-39), y que continuó como tal durante la Edad del Cobre (Esteve 1945: 38-40, y 1962: 26), época en que la comarca se vio densamente poblada a tenor de la abundancia de asentamientos recientemente localizados (Ramos y otros 1989: 21-60).

Para la etapa que ahora nos interesa los datos son escasos y poco precisos, a pesar de que se ha intentado una reconstrucción teórica de la estratigrafía con base en la aplicación de unos valores numéricos aproximativos a las apreciaciones del excavador (Ferreiro 1981 y 1985). No es posible por tanto, en el estado actual de nuestros conocimientos, saber si la crisis de la segunda mitad del siglo VI a.C. que venimos persiguiendo influyó o no, y en qué medida lo pudo hacer, sobre una ciudad que ha sido tenida incluso por sede del gobierno de las poblaciones turdetanas del Bajo Guadalquivir (Pemán 1942: 17. En contra Ferreiro 1982: 159). Pero tenemos al menos la certeza de que el sitio conoció una determinada ocupación durante la segunda Edad del Hierro, porque a ella pertenecen algunos materiales cerámicos de estilo ibérico de los que se ocupó con detenimiento E. Cuadrado (1962). Estos aparecen incluso en la periferia del poblado, área especialmente controlada por las excavaciones (Esteve 1962: 33), por lo que no existen evidencias de que esa recesión afectase en profundidad a la ciudad.

D. Ruiz Mata (1987: 299) ha sostenido la inexistencia en Mesas de Asta de materiales anteriores al siglo 
V a.C., lo que vendría a suponer que a partir de esta fecha se fundaría la ciudad protohistórica. Pero esta hipótesis es difícil de mantener si se analizan con detenimiento algunas de las cerámicas publicadas por Esteve Guerrero, entre ellas las decoradas con retícula bruñida, que el excavador dio a conocer de hecho en la memoria correspondiente a la campaña de 1945-46 por ejemplo (1950: lám. V:13), y que hablan con claridad de un hábitat humano en dicho sitio ya en época orientalizante.

\section{6.- Cerro Naranja}

En el término municipal de Jerez de la Frontera (Cádiz), este yacimiento constituye una de las pocas explotaciones rurales de la segunda Edad del Hierro excavadas hasta la fecha en el Bajo Guadalquivir (González Rodríguez 1985), pues otras se conocen sólo por prospecciones de superficie (Ruiz Delgado 1985: 245). Aunque su cronología fundacional no abarca, en consecuencia, el periodo crítico que ahora nos ocupa, resulta interesante reseñar aquí los resultados de estas investigaciones por las claves que el sitio y su función económica puedan aportar en el análisis de la situción protohistórica de Andalucía occidental.

El asentamiento tiene solamente 1300 metros cuadrados de superficie y un único momento de ocupación. Se diseñó como un solo conjunto, arbitrándose distintas estructuras para usos diversos, que parecen estar relacionados con la explotación de ciertos productos agrícolas (González Rodríguez 1985: 92-93).

A tenor de los materiales cerámicos localizados, este enclave rural debe datarse desde mediados del siglo IV a.C. hasta comienzos del siguiente (González Rodríguez 1985: 95), en coincidencia parcial con la inauguración de otros pocos sitios que aquí se analizan (La Tiñosa y Las Redes por ejemplo) y con la recuperación del hábitat postorientalizante de algunos poblados, como ocurre con Alhonoz.

\section{7.- Cortijo de Ebora}

Aunque los resultados de las excavaciones de Carriazo en el poblado de Ebora (Sanlúcar de Barrameda, Cádiz) no han sido publicados en extensión, los escuetos datos que de él conocemos en lo que concierne a sus distintas fases de ocupación son ciertamente reveladores a la hora de clarificar determinadas circunstancias que rodearon el ocaso del mundo tartesio (Carriazo 1970b y 1973: 326-434).

En el área sondeada a partir del hallazgo del tesoro aparecido junto al caserío de la finca en 1958, Carriazo distinguió tres niveles. Estas capas no reflejan estratos naturales del yacimiento ni fases determinadas del hábitat, ya que se levantaron de forma arbitraria y con una potencia media de $20-30 \mathrm{cms}$. (Carriazo 1970b: 51 y 57). De tal metodología se deriva que el análisis que podamos hacer del poblamiento antiguo tenga que basarse exclusivamente en la valoración de los materiales arqueológicos localizados.

Con base en estos presupuestos resulta difícil por ahora establecer la cronología fundacional del poblado protohistórico. Nos parece que Carriazo cae en cierta contradicción cuando afirma haber encontrado «un fragmento de cerámica oscura y pulimentada, como trozo del borde de una taza, que presenta por el interior unas gruesas fajas bruñidas» (1970: 41) y luego niega por dos veces el hallazgo de cerámica de retícula bruñida (1970: 70). Este documento hablaría de una primera ocupación duramte el Bronce Final o a partir del Hierro Antiguo, porque hoy sabemos que esta especie cerámica no pervivió casi nunca hasta época prerromana. En cualquier caso, el asa de lebes de bronce que lleva como adorno un delfín, que Carriazo fecha en el siglo VII a.C. (1970: 58-60), demostraría una ocupación segura en tiempos orientalizantes, certificada por algún fragmento de cerámica griega datado en el siglo VI a.C. (Carriazo 1970b: 70-71) y tal vez hasta por parte del mismo tesoro, que, en opinión de algunos autores con excepción de Maluquer (1958: 206), no perece contener piezas que puedan llevarse a cronologías posteriores a los 
siglos VI-V a.C. (Blanco De Torrecillas 1959: 56. De La Bandera 1987). La datación orirentalizante para la fundación de Ebora ha sido consecuentemente aceptada en trabajos de síntesis sobre los orígenes de la ocupación protohistórica del territorio cercano a la Bahía de Cádiz (Ruiz Mata 1987a: 299).

El poblamiento tartesio del sitio queda así por lo menos apuntalado con ciertas bases relativamente sólidas. En consecuencia, la fase siguiente debe verse como la continuidad ocupacional del lugar respecto al periodo precedente. Ahora, y a tenor de los materiales localizados en el yacimiento, es cuando la ciudad alcanza un desarrollo de importancia, sobre todo a expensas de una economía basada al parecer más en la pesca y en el comercio que en el sector agropecuario (Carriazo 1970b: 69). Por tanto, la transición desde los tiempos tartesios a los prerromanos no parece que originara en Ebora una especial situación de crisis particular, a no ser que la propia potenciación de las actividades mercantiles y de las relacionadas con el mar deban verse como una búsqueda y pontenciación de nuevas fuentes de recuersos, antes secundarias, o bien que la propia ocultación del tesoro se produjera en tales momentos, reflejando así una importante situación de peligro.

\section{8.- Las Redes}

El hallazgo en Corinto de ánforas iberopúnicas fechadas en el siglo V a.C. (Florido 1984: 426) da crédito a las fuentes literarias que hacen referencia al consumo de salazones gaditanas en la Grecia clásica (De Frutos y otros 1988: 300-301). Sin embargo, la constatación arqueológica más antigua que poseemos hasta la fecha de una factoría de salazones en el sur de España se remonta sólo a la centuria siguiente.

Del siglo IV a.C. es, en efecto, la fundación de la pesquería de Las Redes, en la localidad gaditana de El Puerto de Santa María (De Frutos y otros 1988: 296). No existió allí por tanto actividad económica alguna durante época tartesia, por lo que es imposible constatar en el yacimiento el reflejo directo de la crisis que nos ocupa. Sin embargo, olvidar en este repertorio de sitios unas mínimas referencias a dicho centro industrial nos privaría de unas importantes bases documentales sobre las que luego queremos volver, especialmente para lanzar hipótesis acerca de los pilares económicos en los que se sustentó en parte la recuperación de la economía de los tiempos prerromanos (Ruiz Mata 1987a: 303).

\section{9.- Castillo de Doña Blanca}

No se ha publicado todavía de este poblado una memoria completa de la extensa superficie ya excavada, de manera que las consideraciones que hagamos deben tomarse en este caso todavía con más provisionalidad que las que afectan a otros yacimientos de la lista aquí reseñada. Al parecer, este problema se ve agravado en Doña Blanca por la complicada estratificación del $t e l l$, que ha provocado el cambio de fecha para unos lienzos de su muralla más antigua de unas campañas a otras (Ruiz Mata 1986b: 360; y 1987b: 384).

Tiene además este sitio el valor de poder ser utilizado como reflejo directo de lo que paralelamente pudo acontecer en la inmediata Gadir, de la que sólo conocemos su necrópolis y algunos otros hallazgos de procedencia submarina que, en conjunto, no permiten urgar con profundidad y por vía directa en las consecuencias de la crisis tartesia sobre la colonia tiria (Ruiz Mata 1986a: 242).

A decir del excavador, los acontecimientos del VI a.C. se documentan en Doña Blanca ya desde mediados de dicho siglo, y han quedado reflejados en tres aspectos fundamentales: evolución del repertorio de formas en la cerámica a torno, cierta decadencia constructiva y disminución de la potencia estratigráfica (Ruiz Mata 1986a: 243, y 1987a: 302). También por los mismos momentos se constata la importación de cerámica griega, que en la segunda mitad de esa centuria facilitará la producción local de imitaciones de copas jonias (Ruiz Mata 1987a: 303). 
A tenor de lo conocido hasta ahora en la Bahía de Cádiz, perece que la crisis no tuvo tan graves consecuencias como en el área onubense, pues el siglo $\mathrm{V}$ a.C. se vivió al menos con el esplendor que reflejan los sarcófagos gaditanos (Blanco y Corzo 1981. Kukahn 1951), notándose en Doña Blanca, en cuanto a la cultura material, una evolución sin rupturas de las transformaciones que se habían iniciado casi cien años antes (Ruiz Mata 1987a: 303) e incluso un nuevo florecimiento de la ciudad basado tal vez en la elaboración y comercialización de salazones de pescado (Ruiz Mata 1986a: 243). A esta revitalización puede deberse la reocupación en el siglo IV a.C. de un sector portuario que se había abandonado tres siglos atrás (Ruiz Mata 1987b: 380).

\section{0.- Acinipo}

Debajo de los niveles romanos de Acinipo, yacimiento en las cercanías de Ronda (Málaga), las últimas excavaciones han descubierto una secuencia estratigráfica que refleja una ocupación humana iniciada al menos en la Edad del Cobre, si no antes (Aguayo y otros 1985 y 1986).

Por lo que aquí nos interesa, debe señalarse que entre los estratos de época romana y los de tiempos orientalizantes faltan por completo los de la segunda Edad del Hierro. Este hiato refleja con claridad la desocupación del sitio en época prerromana, al menos en el área hasta ahora excavada y con resultados dados a conocer.

Como la publicación de estas labores arqueológicas no pasa aún de ser unos escuetos informes relativos a las campañas de 1985 y de 1986, en los que no aparecen dibujados los materiales encontrados en cada fase, carecemos de bases sólidas para llevar a cabo una lectura crítica de la interpretación de los excavadores. A pesar de lo cual, alguna información literaria sobre la documentación que caracteriza a los últimos momentos del hábitat protohistórico podría usarse para matizar la fecha propuesta por los autores para dichos niveles.

Los últimos momentos de la ocupación de época orientalizante han sido datados en la segunda mitad del siglo VII a.C. (Aguayo y otros 1985: 302). Pero los materiales que se señalan prodrían ser perfectamente característicos también de la centuria siguiente. De hecho, los soportes con forma anular, que, a decir de los excavadores, en Acinipo se hacen en cerámica a torno y sustituyen a los anteriores a mano y con silueta de carrete, constituyen un elemento que ha sido llevado casi siempre al siglo VI a.C. (Blázquez y Valiente 1981: frag. $n^{\circ} 293$. Escacena 1979-80: 208-209), cuando no al V (Arribas y Arteaga 1975: láms. II:5-7 y IX:38).

$\mathrm{Si}$, como quiere el equipo que viene investigando este poblado (Aguayo y otros 1985: 302; y 1986: 336), el asentamiento protohistórico quedó deshabitado a fines del siglo VII a.C. y no en el siguiente según acabamos de proponer, podría pensarse que el hábitat sufrió los mismos o parecidos problemas que dieron al traste con algunos de los asentamientos fenicios de la costa malagueña que acabaron por aquella fecha o poco después. Recuérdese el caso concreto de Toscanos por ejemplo, que después de esa centuria tuvo una vida efímera si no una auténtica desaparición (Schubart y Arteaga 1986: 512-513. Schubart y otros 1969: 111-113). Pero los excavadores de Acinipo hacen numerosas referencias a las conexiones de sus materiales arqueológicos con los de yacimientos del Bajo Guadalquivir, que se constatan al menos desde la Edad del Bronce (Aguayo y otros 1986: 335). Esta circunstancia sugiere que la ciudad se relacionó más con las tierras interiores de la Baja Andalucía que con las del litoral mediterráneo, de lo que sería fiel reflejo la existencia en Acinipo, entre otras cosas, de cerámicas orientalizantes pintadas con motivos figurativos, especie que resulta hasta ahora casi exclusiva del valle inferior y medio del Guadalquivir (Murillo 1989. Remesal 1975). Y dado que esa crisis de fines del siglo VII a.C. no ha sido aún detectada en los poblados agropecuarios del interior del territorio tartesio, nos parece al menos razonable nuestra sospecha de que el final protohistórico de Acinipo deba llevarse a fines del siglo VI a.C. más que a la centuria anterior. 


\section{1.- Aratispi}

A este yacimiento malagueño rodean las mismas o parecidas circunstancias que al de la Mesa de El Gandul en la provincia de Sevilla, derivadas sobre todo de la escasez de datos dados todavía a conocer. En principio, de la lectura de los informes publicados se deduciría la inexistencia de problemas especiales en los momentos que marcan la transición del mundo tartesio al prerromano (Perdiguero 1986 y 1987). Pero los materiales publicados gráficamente son pocos, lo que priva al lector de la capacidad crítica suficiente para enjuiciar las deducciones del excavador. Por estas últimas sabemos que la ciudad no sólo eludió la crisis del final de los tiempos orientalizantes, sino que afrontó la fase prerromana con el suficiente potencial económico como para permitirle la construcción en pleno siglo IV a.C. de una muralla (Perdiguero 1987: 308).

\section{2.- Riotinto}

Queremos analizar bajo este topónimo unos cuantos sitios que tuvieron que ver fundamentalmente con las explotaciones mineras de la Sierra de Huelva en época protohistórica. Algunos de esos puntos han pasado a la bibliografía arqueológica con nombres distintos, pero constituyen en realidad partes del mismo yacimiento: así, por ejemplo, Cerro Salomón y Quebrantahuesos, que parecen ser barrios de un único poblado. Otros, como ocurre con Chinflón, representan campamentos aislados, sólo ocupados mientras fue productiva la mina que los originó. No se incluyen, por estar fuera de la zona minera propiamente dicha, enclaves que tuvieron desde luego mucho que ver con las explotación, transporte y comercialización de los productos metálicos onubenses, que se tratan aparte: Tejada la Vieja, Niebla, San Bartolomé de Almonte, etc.

En el Cerro Salomón, las tareas de excavación pusieron al descubierto una serie de estructuras que, sin apenas acumulación estratigráfica, delatan un ambiente fechable durante el siglo VII y tal vez parte del VI a.C. gracias a la presencia de ánforas fenicias, cerámicas a mano toscas decoradas con impresiones digitales y motivos incisos, cuencos de cerámica gris con el borde engrosado hacia el interior, pithoi de cerámica a torno, etc. (Blanco y otros 1969: 126 ss.; y 1970: 16 ss.). Concretan sobre todo la cronología los vasos trípodes, las lucernas de uno o dos picos y los platos de barniz rojo (Blanco y otros 1969: 134136).

En Quebrantahuesos, el hábitat se ve cronológicamente ampliado tanto en sus inicios como en su etapa final. De esta última, la que ahora nos interesa, cabe destacar su prolongación hasta los siglos V o IV a.C. (Pellicer 1983: 61 y 85). De hecho, el estrato 2 contenía un fragmento de crátera de campana del siglo IV a.C. (Pellicer 1983: 85), que tampoco iría mal a fines del siglo anterior, ya que desde el tercer cuarto del mismo los modelos griegos con silueta acampanada venían sustituyendo, como es bien sabido, a los más antiguos de columnas en casi todo el Mediterráneo; y, además, el resto de los materiales de ese estrato 2 parecen exigir cronologías ligeramente más altas para esta capa, pues el mismo excavador señala el relativo arcaísmo de las ánforas, cuyos paralelos tipológicos se fechan en los siglos VI y V a.C. (Pellicer 1983: 82). Por último, el borde de pátera del corte $\mathrm{C} / 5$ coloca al estrato 1 , el más reciente, hacia el siglo IV a.C., sin que deban llevarse obligatoriamente a tal fecha todos los hallazgos de dicho nivel, pues existen en él indicios de remociones dado su carácter superficial (Pellicer 1983: 63 y 85). Contando con la ausencia de materiales ibéricos claramente asignables a los siglos V y IV a.C. y con la citada antigüedad de las ánforas hasta las capas más modernas, cabría incluso la posibilidad de que el final de la ocupación estable de Quebrantahuesos se produjera a mediados o a finales del siglo V a.C., constituyendo los dos fragmentos griegos los testimonios más recientes llegados al poblado desde el mundo exterior. 
El el término de Zalamea la Real, Chinflón es en realidad, más que un poblado, un hábitat transitorio que duró lo que la mina de trinchera contigua (Pellicer y Hurtado 1980). Un intento de remontar en exceso su cronología (Blanco y Rothenberg 1981: 38-38) ha chocado frontalmente con la documentación exhumada por los excavadores, que no conoce paralelos anteriores al siglo IX a.C. y sí en cambio de los siglos VIII y VII a.C. (Pellicer 1987-88: 461-483. Ruiz Mata 1979: 3-19).

Aunque parte de la crisis que acabaría con el mundo tartesio afectó profundamente al sector metalúrgico, paradójicamente de estos testimonios relacionados con las explotaciones mineras de las tierras onubenses poca información puede obtenerse para el problema que nos ocupa. Es cierto que Cerro Salomón-Quebrantahuesos constituye un asentamiento cuya muerte coincidiría sólo a grandes rasgos con los tiempos finales de Tartesos, pero estas circunstancias no concurren en el caso de Chinflón. Quienes conocen la historia más reciente (moderna y contemporánea) del foco minero de Riotinto saben que la zona ha conocido un trasiego constante de puntos en explotación. Si los yacimientos antiguos que hoy encuentra la arqueología son los sitios ocupados por los mineros y sus áreas de servicio, es lógico pensar que el agotamiento de determinados filones condujo a la mudanza de dichos asentamientos hacia las cercanías de otras vetas. En consecuencia, debemos deducir de tal hecho la imposibilidad de correlacionar muy directamente fenómenos generales observados en la Protohistoria con casos particulares detectados en puntos aislados de Riotinto. Por lo demás, aquella zona ha conocido históricamente un ritmo creciente de destrucción de los restos arqueológicos en aras de la paralela potenciación de las extracciones de mineral; de ahí que la información que hoy nos queda sea en exceso parcial. Por consiguiente, poner en conexión la muerte durante el siglo VII a.C. de algunas colonias fenicias del Mediodía español con un hipotético final en esa misma centuria de la mina de Chinflón constituye un peligroso juego de azar. Sí parece en cambio razonable sostener que el casi absoluto vacío de información que sobre la explotación del foco minero de Riotinto se tiene para los tiempos prerromanos, obedezca a la profunda regresión que dicho sector económico experimentó con la muerte de Tartesos (Fernández Jurado 1986: 168, y 1987a: 316. Ruiz Mata 1987a: 303). Esto no implica en ningún caso rechazar la idea de una explotación residual en la segunda Edad del Hierro, que pudo mantener parcialmente en vida ciudades que, como Niebla, habían vivido en tiempos orientalizantes en gran medida del control del mineral en su ruta de salida hacia el puerto de Huelva (Belén y Escacena e.p.c).

\section{3.- Niebla}

Las excavaciones practicadas en la antigua Ilipula, junto a las murallas del sector de la «Puerta de Sevilla», han ofrecido una estratigrafía ininterrumpida desde la fundación de la ciudad hasta época árabe (Belén y otros 1983. Belán y Escacena e.p.c).

El hábitat conoció unos primeros tanteos de ocupación prehistórica durante el Calcolítico y, tal vez, el Bronce Medio. Pero no fue hasta comienzos del siglo VII a.C. cuando se inaugura el asentamiento que da origen a la concentración urbana histórica. Desde este primer momento, bien detectado en la cata 8 , existen evidencias claras de la vinculación de Niebla con la explotación de los metales onubenses.

La transición del Hierro I al II quedó registrada entre los niveles IX y VIII de dicho sondeo. En estos estratos no se observan problemas especiales relacionados con abandonos o destrucciones. De ahí que tengamos que concluir admitiendo que la ciudad logró de alguna forma esquivar la crisis que paralelamente venía afectando a otros muchos enclaves tartesios. Si la burla de esta depresión se basó en la explotación, aunque fuera residual, de los metales del foco de Riotinto, o si tuvo como pilar fundamental la reorientación de la economía hacia el sector agropecuario como única fuente de recursos, es algo que aún está por investigar. En cualquier caso, no debe olvidarse que la calidad de las tierras que se extienden hoy al sur 
del caso urbano permite una agricultura de secano de cierta importancia, y las zonas septentrionales una significativa facilidad para su aprovechamiento ganadero.

\section{4.- Tejada la Vieja}

Nacido en el siglo VIII a.C., este poblado onubense basó su vida en principio en las actividades metalúrgicas y, sobre todo, mineras (Fernández Jurado 1986: 158), aunque no sólo como productor sino también como intermediario en la salida de la plata de las minas de Aznalcóllar hacia la desembocadura del Guadalquivir y Cádiz.

La periodización establecida con base en su secuencia estratigráfica y en sus materiales (Fernández Jurado 1987b: 153-175) ha definido tres fases, dos de las cuales pertenecen a época tartesia y la restante a la segunda Edad del Hierro.

A decir de su excavador, el siglo VI a.C. viene caracterizado en Tejada por una profunda crisis del sector minero-metalúrgico. Esta depresión puede centrarse a mediados de dicha centuria, y provocó un relativo abandono de las actividades relacionadas con la producción y comercialización de los metales, hasta el punto de que la población empieza a buscar otras fuentes de recursos en el sector agropecuario, antes relegado a un papel poco importante. Durante la segunda mitad del siglo VI y la primera del V a.C. Tejada repartió más o menos al cincuenta por ciento sus pilares económicos entre esos dos negocios; pero en la última fase de su existencia, esto es, desde mediados del siglo $\mathrm{V}$ a mediados del IV a.C., las actividaes minero-metalúrgicas se abandonan prácticamente por completo, decayendo asimismo los contactos comerciales con la costa, tan importantes en las etapas anteriores.

Por lo que se refiere a algunos aspectos de su urbanística, debe señalarse la constatación de una importante remodelación de sus edificios tras la fase II, es decir, después de la entrada en el periodo crítico que ahora nos ocupa. Dicho replanteamiento afectó a la estructura de las construcciones y, posiblemente, también a su función. Son de esta época igualmente los contrafuertes trapezoidales de la muralla, un reforzamiento que había sido precedido de otro anterior datado en los últimos años del siglo VI a.C. (Fernández Jurado 1991: 58).

\section{5.- San Bartolomé}

El poblado de San Bartolomé, en Almonte (Huelva), constituye uno de los pocos sitios analizados en este trabajo con economía especializada en un único sector, en este caso el metalúrgico (Ruiz Mata 1981. Ruiz Mata y Fernández Jurado 1986). Esta característica matiza algunas de las deducciones que aquí podamos hacer acerca de su valoración en el problema general que tratamos: la crisis tartesia del siglo VI a.C.

San Bartolomé tuvo una primera ocupación calcolítica que no parece el gérmen del siguiente poblado protohistórico, ya que entre uno y otro horizontes existe un hiato de al menos un milenio de duración (Ruiz Mata 1986c: 541). El asentamiento tartesio se inicia al compás de la presencia fenicia en el occidente mediterráneo, y acaba muy a finales del siglo VII a.C. o a comienzos de la centuria siguiente (Ruiz Mata y Fernández Jurado 1986: 231-237). En función de la cronología propuesta en la extensa memoria de excavaciones recién citada, la fecha en que este asentamiento muere no coincide, pues, con el periodo crítico que ahora analizamos, de manera que ha de ponerse en relación con problemas de otra índole. Si el poblado estuvo dedicado, como parece, sólo al proceso de obtención de plata y a darle salida a ésta hacia el mar, en busca de la colonia fenicia de Gadir, las causas de su declive pudieron deberse a fenómenos particulares que tuvieran que ver con los requisitos técnicos necesarios en la extracción de los minerales 
o con las circunstancias del comercio de los productos metálicos. Se ha hablado de que la crisis metalúrgica de Tartesos tuvo por base la necesidad de aplicar unas innovaciones técnicas en el foco minero de Riotinto no controladas por las poblaciones protohistóricas (Fernández Jurado 1986: 170; y 1987a: 316). Pero la plata obtenida en San Bartolomé procedía al parecer del foco minero de Aznalcóllar, en la provincia de Sevilla (Fernández Jurado y Ruiz Mata 1985: 24. Ruiz Mata y Fernández Jurado 1986: 251-261). Por otra parte, la coincidencia cronológica entre el final de San Bartolomé y la crisis que acabaría con Toscanos levanta sospechas más que suficientes para pensar en una causa común: la caída de Tiro y el consiguiente final de la demanda de plata a Tartesos por parte de los mercados del Mediterráneo oriental. En cualquier caso, resulta difícil aún concretar estas cuestiones a falta de mayor precisión en la cronología final del asentamiento, que se ha llegado a fechar en momentos algo posteriores a los aquí apuntados (Ruiz Mata 1987a: 303) e incluso sólo a finales del siglo VII a.C.(Fernández Jurado y Ruiz Mata 1985: 34 Y 41), sin prolongación hasta el VI en disonancia con lo que uno de sus excavadores ha llegado a publicar en alguna ocasión (Fernández Jurado 1986: 157 y 168).

\section{6.- Aljaraque}

De este asentamiento onubense conocemos aún escasos datos, pues la única estratigrafía hasta hoy obtenida no dio abundante documentación (Blázquez y otros 1971). Con las reservas lógicas que impone lo reducido de la excavación, se puede admitir una secuencia dividida, especialmente en la cudrícula 6 , en cuatro grandes paquetes sedimentarios.

Al estrato 4, fechado por los excavadores en el siglo VII a.C., se superpone inmediatamente el 3, que cerámicas áticas permiten datar a fines del siglo $\mathrm{V}$ y durante todo el IV a.C. (Blázquez y otros 1971: 324 ss.). Al estrato 2 vendría bien el siglo III a.C., pero es necesario apuntar la posibilidad de que existan en él materiales revueltos procedentes de fases más antiguas, pues esto se observa también en la capa superior, donde las decoraciones de algunos fragmentos de cerámica apuntan a cronologías orientalizantes (Blázquez y otros 1971: fig. 8:84-85).

Del análisis estratigráfico de esta secuencia se deduce la necesidad de usarla con extremada cautela a la hora de valorar los datos relativos al final del mundo tartesio. Porque entre los documentos conocidos existen datos contradictorios acerca de la existencia o no en el yacimiento de niveles asignables con claridad al siglo VI y a gran parte del V a.C.; a lo que se añade que, con posterioridad a estos trabajos de campo, uno de los excavadores ha vinculado la fundación de este asentamiento de Aljaraque a cronologías algo posteriores a las primeramente obtenidas, centrando su nacimiento a fines del siglo VI a.C. sin argumentar las bases de esta nueva sugerencia (Ruiz Mata 1987a: 303).

\section{7.- Huelva}

Una obra relativamente reciente sobre la Huelva tartesia compila toda una extensa serie de trabajos de campo y de interpretación anteriores dedicados a ese asentamiento (Fernández Jurado 1988-89). Por dos razones esta síntesis nos ahorra una descripción pormenorizada de cuantas actuaciones arqueológicas han afectado a la Huelva protohistórica, a la vez que nos evita citar constantemente toda la bibliografía que en ella se recoge: en primer lugar, porque dichas excavaciones han constituido en gran medida trabajos del mismo autor y/o de su equipo; y en segundo, porque coindicimos en líneas generales con Fernández Jurado en la valoración global que hace de la crisis que acabaría con la Huelva de tiempos orientalizantes y en la interpretación de las bases que servirían de sostén a la Onuba turdetana posterior.

En síntesis, parece que hoy estamos en condiciones de afirmar que el esplendor tartesio de la ciudad 
se sostuvo en el control de las exportaciones de los metales de Riotinto en el marco del comercio «internacional» del momento, especialmente el que tuvo por base la demanda de plata desde Oriente a través de intermediarios fenicios. Pero la alta especialización de Huelva en esta actividad fue a su vez la causa de su declive. Sería lógico que éste se iniciara ya en la primera mitad del siglo VI a.C., cuando, a la caída de Tiro en manos asirias, el comercio de la plata entre Oriente y Occidente sufre un serio retroceso. Pero el hecho de que todavía durante algunos años Huelva mantenga su vitalidad sin necesidad de transformar drásticamente su economía, retrasando los efectos más hondos de esta depresión hasta el último tercio del siglo VI a.C. como demuestra el cese de las importaciones de cerámica griega, sugiere que el comercio de los metales debió tener una base importante también en la explotación del cobre, y/o que existió, aparte de la demanda originada en las ciudades fenicias de Asia, un mercado local y regional significativo, al que se sumaría una demanda atlántica no menos despreciable.

La Huelva postorientalizante carece hasta la fecha de tanta información como la tartesia. Pero la documentación permite ya al menos mantener la hipótesis de que la ciudad transformó sustancialmente su economía, diversificando sus fuentes de ingresos mediante una explotación importante de los recursos marinos. Esta mirada al mar supuso una solución que partía de la base de reconocer una pérdida del papel preponderante que su economía había desempañado en la primera Edad del Hierro, papel que quedaría reservado en lo sucesivo a Cádiz y su bahía (Ruiz Mata 1987a).

\section{8.- La Tiñosa}

Con ocupación exclusiva durante la segunda Edad del Hierro, este yacimiento onubense se sitúa en el término municipal de Lepe, a sólo unos cientos de metros de la costa actual pero en la misma línea del litoral antiguo (Belén y Fernández-Miranda 1978).

Los distintos cortes estratigráficos practicados sólo han proporcionado una secuencia clara en la cata 3. Según este sondeo, el poblamiento da comienzo en la primera mitad del siglo IV a.C., fecha obtenida gracias al hallazgo de cerámica ática de barniz negro (Belén y Fernández-Miranda 1978: 277).

De La Tiñosa debe subrayarse, por las implicaciones en el problema que abordamos, su situación y su función económica, ambas relacionadas con la explotación de los recursos marinos (Belén y FernándezMiranda 1978: 289). Tal vez fue ésta la razón por la que se usaron en el yacimientos tantas ánforas relacionables con la elaboración y envasado de salazones (Belén y Fernández-Miranda 1978: figs. 12, 15 , 22 y 35), cuya tipología y cronología enlazan fielmente con el mundo del Bajo Guadalquivir (Pellicer 1978: 379 ss., figs. 5 ss.).

\section{ALGUNAS REFLEXIONES FINALES}

A pesar de que la crisis de los últimos tiempos del mundo tartesio dejó claro reflejo en el tamaño y en las características del poblamiento, según demuestran las estratigrafías reseñadas, todavía no es posible, en el estado actual de nuestros conocimientos, aquilatar con precisión una serie de cuestiones imprescindibles para valorar el fenómeno en su justa medida. Con todo, no resulta vana la elaboración de una serie de hipótesis que, partiendo de la documentación hasta ahora disponible, sirva al menos para orientar futuras investigaciones.

Una de las condiciones que más frenan la enumeración de un cuerpo de características comunes en la respuesta dada por las poblaciones protohistóricas de Andalucía occidental a la crisis del siglo VI a.C. deriva de las imprecisiones cronológicas. La imposibilidad de ajustar las fechas de los yacimientos y de sus correspondientes estratos con los métodos de que dispone la arqueología de esta estapa es un reto 
metodológico todavía no resuelto. Si bien en algunos puntos las importaciones de cerámica griega arcaica han permitido, como ocurre en Huelva por ejemplo, tener un esqueleto relativamente seguro en el que apoyar ese entramado cronológico, la mayor parte de los lugares excavados carece de tales pilares. Una solución razonable a este problema sería la aplicación automática de la fecha de esos contextos con materiales griegos a aquellos otros que, siendo semejantes, carecieran de tales importaciones. Pero parece que muchos arqueólogos, guiándose más bien por una especie de tendencia incomprensible a creer que la Historia es más importante si es más antigua, han relegado a un segundo plano ese razonamiento que a nosotros nos parece tan lógico. En cualquier caso, la posibilidad de relacionar los fenómenos demográficos observados en los asentamientos con hechos históricos cuya fecha conocemos bien a través de documentos escritos, exige tal grado de precisión cronológica a la arqueología protohistórica, que aquel otro problema queda en parte olvidado. Hemos visto este asunto planteado con toda crudeza en las distintas fechas propuestas para ofrecer una datación precisa al final del poblado metalúrgico de San Bartolomé de Almonte, por ejemplo; y no escapa a nuestra reflexión las contradicciones cronológicas entre las fechas dispares aplicadas por distintos autores a la hora de datar los niveles más superficiales de la Mesa de Setefilla, cuestión en la que, como se vio, nosotros mismos nos hemos visto implicados muy directamente.

De todo esto se deriva la imposibilidad de fechar con la nitidez que a todos nos gustaría la crisis que acabó con Tartesos. En consecuencia, las «leyes» generales que podamos dedudir del estudio pormenorizado de los hábitats antes tratados estarán condicionadas en todo momento a las posibles matizaciones cronológicas que un futuro con métodos de datación más precisos pueda depararnos. No obstante, hoy pueden lanzarse ya algunas hipótesis interpretativas relativamente seguras.

Desde la explosión demográfica que el mundo tartesio experimentó durante los siglos IX y VIII a.C., la Baja Andalucía conoció una situación de bonanza económica que duró, sin apenas problemas detectables, hasta el siglo VI a.C. A comienzos de esta centuria, las consecuencias ocasionadas por la situación del Próximo Oriente asiático, con la caída de Tiro, supondrán un primer revés para la economía tartesia. Parece ser que la conquista de Tiro produjo, en primer lugar, la muerte o la decadencia de algunos de los enclaves fenicios de la costa suroriental hispana, que, por tanto, deberían tenerse por satélites de la política económica de los fenicios de Oriente en el extremo occidental del Mediterráneo. Como consecuencia directa de estos hechos, los enclaves del interior tartesio que deberían experimentar una primera situción de penuria corresponderían a aquellos puntos que se vieron obligados a dejar de abastecer la inicial demanda de plata por parte de las metrópolis orientales. Como San Bartolomé de Almonte se dedicó con exclusividad a la elaboración de plata, parece plausible relacionar su final con la interrupción de dicho comercio. Y si la materia prima allí elaborada procedía del foco minero de Aznalcóllar a través de Tejada, deberíamos concluir que también los puntos de origen y las escalas de la ruta se vieron profundamente afectados por esta crisis. Sin embargo, dejando al margen el caso de Aznalcóllar, cuyas explotaciones mineras prehistóricas y protohistóricas no conocemos aún, debe recordarse que Tejada la Vieja no murió del todo como consecuencia de dicha recesión, sino que se mantuvo con vida aún durante dos siglos. Las claves de este comportamiento diferencial entre el lugar de destino (San Bartolomé) y el principal hito de la ruta (Tejada) deben estar sin duda en las características geográficas de los sitios que esos poblados ocupan, que permitirían en un caso e impedirían en el otro la ramificación de los vectores económicos. En tal sentido, si Tejada logró burlar en cierta medida una seria amenaza de muerte, fue al parecer, como bien ha señalado su excavador, acudiendo a una economía agropecuaria cada vez más importante en relación con la minero-metalúrgica; y si San Bartolomé dejó de existir por completo fue por la pobreza de las tierras arenosas sobre las que se asentaba, generosas en la oferta de combustible vegetal para los hornos de fundición pero edáficamente ralas para lograr en ellas cosechas mínimamente rentables. Volveremos sobre este asunto al decir unas cuantas cosas sobre Niebla. 
A primera vista, y como consecuencia del análisis de la situación descrita, parece deducirse que la primera crisis que la arqueología detecta en el mundo tartesio afectó a los intereses fenicios que detentaban el monopolio del comercio de la plata. En la ruta hacia Oriente de esos productos metálicos desempeñó al parecer un papel crucial el poblado de Doña Blanca. No obstante, hasta hoy no se ha rastreado una recesión económica seria en dicho enclave en la primera mitad del siglo VI a.C., lo que sugiere que sus fuentes de ingreso deberían estar ya en esa fecha muy diversificadas. Una segunda conclusión puede aún colegirse de este análisis: que el primer declive del sector minero-metalúrgico de Andalucía occidental en época tartesia fue un bache comercial, que tuvo como base una interrupción de la demanda de sus productos por parte de sus principales clientes; de donde debe descartarse de momento una relación directa de dicha depresión con problemas técnicos derivados de las características y exigencias de explotación de las zonas mineras.

Si Onuba sufrió esta ruptura de la demanda, como parece, debería detectarse arqueológicamente un retroceso significativo centrado en la primera mitad del siglo VI a.C., lo que aún no se ha constatado. Como Doña Blanca, tal vez también Huelva había huído a tiempo de una economía monopolizada por el sector minero-metalúrgico, o bien había extendido su clientela a otros ámbitos menos vinculados a las metrópolis orientales. En este segundo caso, una hipótesis explicativa posible consistiría en imaginar que, por su privilegiada posición oceánica, no sólo abasteció de metales al comercio fenicio, sino que satisfizo el mercado occidental atlántico y la propia demanda interna de Tartesos. Si la situación crítica no le llegó hasta finales de siglo pudo ser de nuevo por el cese de este otro mercado, más relacionado tal vez con el cobre que con los metales nobles. En cualquier caso, y teniendo siempre muy presentes las observaciones que hicimos acerca del comportaniiento peculiar de la ocupación del territorio en la sierra minera onubense, debe recordarse que el poblamiento del Cerro Salomón queda interrumpido a comienzos del siglo VI a.C., continuándose el hábitat sólo en el sector de Quebrantahuesos.

Por la ruta de salida al mar que Huelva controlaba se movían los productos de Riotinto, haciendo escala a la altura de Niebla, donde posiblemente las mercancías podían embarcarse ya en naves fluviales en busca del puerto onubense. Hasta hoy, Niebla no ha dado muestras de una crisis significativa en el tránsito de la primera a la segunda Edad del Hierro, a no ser que sean erróneos los cálculos cronológicos establecidos para la interfacies de los estratos X y IX, que en principio se ha datado entre finales del siglo VII a.C. y comienzos del siguiente, $y$ donde se ha señalado una «cronología distanciada» entre ambos niveles (Belén y Escacena e.p.c) que podría interpretarse como un posible hiato. Parece impensable suponer a esta ciudad libre de tal crisis cuando ésta se aprecia al inicio y al final de la ruta de la que Niebla es escala, es decir, en la zona de minas y en el puerto «internacional» que da salida marítima a los metales, el de Huelva. En consecuencia, como ocurre en Tejada, tal vez futuros estudios sobre la Niebla protohistórica demuestren que la ciudad había explotado desde su fundación otros sectores económicos. Recuérdese que desde este enclave se dominaba una rica comarca agrícola al sur del casco urbano y una no menos despreciable zona ganadera en su flanco septendrional. De cualquier forma, y a pesar de que las excavaciones llevadas a cabo en las cercanías del sector de la muralla almorávide conocido como «Puerta de Sevilla» no han revelado muestras claras de un posible despoblamiento total parecido al de Tejada, la refundación que sugiere el nombre iberorromano (Ilipula) que la numismática y los textos latinos nos han transmitido, que podría fecharse sólo a partir de fines del siglo III a.C. en atención a un fenómeno general de penetraciones ibéricas que afecta a la Baja Andalucía en esos momentos (Escacena 1992), apunta la posible existencia de un corte ocupacional anterior a esa fecha como una explicación posible. Al igual que la crisis de la vía que desembocaba en San Bartolomé de Almonte, también la de este otro camino parece tener, pues, más tintes comerciales que tecnológicos.

Lo que dio al traste con la explotación de los metales onubenses no parece que fuera, en consecuencia, 
la dificultad de su extracción en las minas, sino la ruptura o, al menos, la disminución de la demanda desde las áreas que antes los habían solicitado. Para comprender el caso ahora de la propia Onuba, es necesario consecuentemente abordar el estudio de la sitaución en los territorio internos del mundo tartesio: las áreas más fértiles del Guadalquivir inferior y medio.

En la depresión bética, las comarcas del valle medio habían conocido un auge demográfico comparable al del foco bajoandaluz. A tal extremo había conducido este floruit, que hoy se tienen registrados en la provincia de Córdoba fenómenos expansivos en la ocupación de tierras más intensos que los del propio núcleo tartesio por excelencia, el del Bajo Guadalquivir (Murillo y otros 1989), con prolongaciones hacia la provincia de Jaén (Ruiz Rodríguez y otros 1991: 118). Pero tales asentamientos, o no tuvieron continuidad en época ibérica, o experimentaron grandes transformaciones en sus estructuras sociales y económicas en el tránsito de la primera a la segunda Edad del Hierro (Ruiz Rodríguez y otros 1991: 119); en resumen, sufrieron cambios drásticos a fines del siglo VI a.C., que no se limitan sólo a la elaboración de refuerzos en sus murallas aunque éstos se hayan constatado en ciertos puntos, según se aprecia en Torre Paredones (Cunliffe y Fernández Castro 1987: 198) o en Puente Tablas (Ruiz Rodríguez y Molinos 1986: 407). Sirva también, como ejemplo de esta crisis, el caso de Monturque, donde los niveles catalogados como ibéricos apenas se constatan tras una secuencia que, iniciada en el Calcolítico, llega holgadamente a tiempos orientalizantes (López Palomo 1987: 191).

Por lo que se refiere al Bajo Guadalquivir, ya hemos tenido ocasión de comprobar cómo y en qué proporciones la referida situación crítica hace mella en cada sitio de los hasta ahora excavados. La documentación revela la existencia de un periodo de decadencia económica y demográfica a fines del siglo VI a.C. que provoca en algunos casos un total abandono de poblados que habían estado en pleno auge durante la fase orientalizante, y en otras ocasiones al menos una considerable reducción de su tamaño. En Setefilla por ejemplo, los distintos sondeos practicados en la meseta que sirve de soporte al hábitat han mostrado una máxima expansión urbana durante los siglos VII y VI a.C., seguida de una reducción de la superficie poblada al comienzos del Hierro reciente, que sólo ocupa débilmente el recinto cerrado en la actualidad por la fortaleza medieval. En otras ocasiones asistimos tal vez a la muerte total de algunos núcleos, como sugiere hasta el momento El Carambolo entre otros. Pero otras veces se reocupan algunos despoblados tras largo tiempo de abandono, caso observable en Alhonoz y, más al este, en Acinipo.

En síntesis, cabe resumir la situación presentando un panorama que en nada debió favorecer a los focos productores de metal del área onubense. Si las poblaciones del Guadalquivir medio e inferior, pero sobre todo las de esta última zona, tenían en el foco minero de Riotinto su principal proveedor de cobre, de plata y de oro, el declive experimentado por las aldeas y ciudades agrícolas y ganaderas del valle debió originar una mengua considerable de la demanda interna en el mercado metalúrgico tartesio. De ahí que la fecha de ese cortocircuito, que básicamente corresponde a la segunda mitad del siglo VI a.C. marque la decadencia final, por lo que se refiere a los tiempos tartesios, de la ciudad (Huelva) que controlaba la salida de esos productos y, en consecuencia, la muerte de su rica fase orientalizante. Agotado el mercado exterior tras la caída de Tiro y el interior a causa de esta otra crisis (¿agropecuaria?) de los ricos enclaves del Guadalquivir, a Huelva no le quedó más salida que la búsqueda en la mar de sus reservas piscícolas, que siempre han dado para vivir pero casi nunca para producir grandes excedentes ni acopio de riquezas.

La misma solución encontrada por la Onuba turdetana postartesia para no desaparecer del todo fue adoptada también por el foco gaditano, que en la segunda Edad del Hierro conocería, ahora bajo una Gadir libre de grandes competidores peninsulares, el control exclusivo del comercio de los productos pesqueros, y para ello la instauración, como en el caso estudiado de Las Redes, de factorías de salazones que aparecen, en esta zona, como casi los únicos puntos de nueva fundación tras la muerte de Tartesos.

El hecho de que en tiempos prerromanos, y en el marco general del oeste andaluz, sólo se inauguraran 
nuevos hábitats prácticamente en el litoral (recuérdese también el caso reseñado de La Tiñosa), revela que las poblaciones bajoandaluzas del Hierro Reciente lograron encontrar en el mar una fuente de recursos relativamente segura. Ésta debió de constituir la razón por la que tal vez el periodo crítico fue superado con cierta facilidad por otras poblaciones que, aun estando en el interior de ese territorio, se encontraban al pie mismo del Guadalquivir, río que les permitiría, en el caso por ejemplo del Macareno, de Italica, de la propia Sevilla y de Lebrija, solventar los profundos problemas económicos que la región venía padeciendo. Que esta superación no estuvo exenta de traumas parece certificarlo la propia ciudad de Nabrissa, en la que vimos una reducción notable de su extensión urbana al comparar la excavación de Huerto Pimentel con la de la Alcazaba. Puede que a este mismo calor que proporcionaba la pesca se arrimaran también Asta Regia y Ebora, punto este último donde ya Carriazo encontrara claros indicios de un abundante consumo de peces. El acudir a la pesca fluvial y marítima en momentos de desajuste económico tiene, como los prehistoriadores bien saben, raíces que arrancan al menos del Epipaleolítico, y en el caso de la región que ahora nos ocupa fue una solución tal vez practicada ya en esa fecha (Caro y otros 1986: 172) y en los momentos de transición del Calcolítico al Bronce (Escacena e.p.).

Si Montemolín y Alhonoz, entre otros sitios, fueron repoblados de nuevo en época prerromana, como así parece desprenderse por lo menos del segundo caso, deberá admitirse que los sectores más vinculados a los asuntos rurales, base económica evidente de los territorios que estos poblados controlan, también alcanzaron con el tiempo una recuperación importante, que duraría hasta momentos romanos según se deduce del paisaje pintado por Estrabón $(I I I, 2,6)$ cuando describe la Turdetania. Si en este renacer jugó algún papel el Norte de Africa es algo todavía no sopesado suficientemente en el terreno arqueológico, pero de alguna forma sugerido por los textos escritos y por los ímpetus de la expansión cartaginesa en esta etapa (De Frutos 1991: 110-111). En este sentido, el yacimiento jerezano del Cerro Naranja ofrece un ejemplo casi único hasta la fecha de sitio fundado ex novo con vistas a la explotación del medio rural. Tal vez en las innovaciones técnicas en él encontradas, materializadas en estructuras e ingenios al parecer no conocidos hasta entonces en el mundo protohistórico meridional, pueda verse algún día la influencia de los importantes cocimientos agropecuarios del mundo púnico helenístico sobre el sur de Hispania, y en el conjunto de tales logros tecnológicos y de algunas fundaciones de hábitats un verdadero apoyo documental a la afirmación estraboniana de que los Fenicios poseían comunidades en la mayor parte de las ciudades de los Turdetanos (Estr. III,2,13).

Cuando se rastrean otras posibles huellas que el final del mundo tartesio dejó para el futuro, no escapan a nuestras sospechas de que existieron acontecimientos violentos en dicho trance tres fenómenos de alguna forma apuntados en el tratamiento particular de los yacimientos reseñados en nuestra lista: la ocultación de tesoros, los niveles de incendio y la construcción de sistemas defensivos en las ciudades; todos ellos datables en la segunda mitad del siglo VI a.C. aproximadamente.

El acto de esconder conjuntos de joyas que, como las del Carambolo o como las de Ebora, no proceden de contextos funerarios, parece denotar un momento de peligro a fines de la etapa orientalizante. Que, por lo que se refiere al devenir histórico de Tartesos, esta grave situación se produjo sólo en ese momento puede sugerirlo el hecho de la inexistencia de otros tesoros asignables a tiempos anteriores dentro de la secuencia cronológica del Bronce Final y del Hierro Antiguo en Andalucía occidental. En lo tocante a los niveles de incendio, siempre desde luego de muy compleja explicación por el reducido tamaño de las excavaciones, ya Blanco relacionó con la transición de Tartesos al mundo prerromano una capa quemada de la Colina de los Quemados y otra de la misma fecha de Ategua (Blanco 1983: 120); y recuérdese que también El Carambolo contenía un grueso estrato de cenizas que precedió a la ocultación del tesoro, y que en Carmona un episodio de abandono precipitado a causa del fuego, captado tanto en las excavaciones de Raddatz y Carriazo como en las de Pellicer y Amores, quedó fechado en la segunda mitad del siglo VI a.C. En tercer 
lugar, los sitios de Lebrija y de Carmona conocieron la construcción de estructuras defensivas por estos momentos, a las que debe sumarse el reforzamiento de la muralla de Tejada la Vieja, por citar sólo algunos casos de la Baja Andalucía.

$\mathrm{Al}$ analizar la crisis de fines del mundo tartesio a través de las huellas arqueológicas que produjo en la ocupación del territorio, sorprende no poco su enorme distribución geográfica. Indicamos en las líneas que introducen nuestro trabajo que el marco estudiado se limitaría fundamentalmente a la región de la Baja Andalucía, pero no podemos resistir ahora la tentación, también anunciada entonces, de hacer al menos una breve alusión a yacimientos que, como el Cerro de la Mora (Pastor y otros 1981) o el del Real (Pellicer y Schüle 1966), en la provincia de Granada, o el de Andújar (Sotomayor y otros 1981), en la de Jaén, experimentaron fenómenos similares por la misma época. En la raíz de un problema de tan profunda y extensa repercusión no se encontraría una sola causa, sino que tal vez fueron varios los factores que contribuyeron en mayor o menor medida a generar ese profundo declive (González Wagner 1983: 29-30). Si aquí hemos insistido más en los aspectos minero-metalúrgicos de esa crisis ha sido quizás por la fecunda tradición con que dicho tema cuenta en la historiografía tartesia. Pero resulta problemático admitir que el desplome de esta actividad sea causa de la depresión demográfica en las tierras interiores del Guadalquivir, donde la población debía de estar dedicada en sus mayor parte a otros quehaceres. De ahí que hayamos pensado alguna vez en una recesión del sector agropecuario (Escacena 1987a: 297). El asunto está por investigar, y los avances en esta línea dependerán estrechamente de los resultados que los análisis faunísticos y polínicos logren ofrecer en futuros trabajos. En éste sólo hemos pretendido, en la medida de nuestras posibilidades, presentar el panorama dibujado hasta la fecha por los puntos excavados, a la vez que llevar a cabo unas cuantas reflexiones sobre lo que a primera vista esta situación provoca en quien pretende acercarse a su conocimiento.

\section{BIBLIOGRAFÍA}

AGUAYO, P. y otros (1985): «El yacimiento pre y protohistórico de Acinipo (Ronda, Málaga). Campaña de 1985», Anuario Arqueológico de Andalucía /1985. II, Actividades Sistemáticas: 294-304. (1986): «Excavaciones en el yacimiento pre y protohistórico de Acinipo: (Ronda, Málaga)». Anuario Arqueológico de Andalucía / 1986. II, Actividades Sistemáticas: 333-337.

AMORES, F. (1982): Carta Arqueológica de Los Alcores (Sevilla). Sevilla, Ed. Diputación Provincial. ARRIBAS, A. y ARTEAGA, O. (1975): El yacimiento fenicio de la desembocadura del río Guadalhorce (Málaga). Granada (Cuadernos de Prehistoria de la Universidad de Granada. Serie Monográfica n²). AUBET, M.E. (1975): La necrópolis de Setefilla en Lora del Río (Sevilla). Barcelona, C.S.I.C.

(1982): «Cerámicas polícromas con motivos figurados de Setefilla (Sevilla)», En Homenaje a Conchita Fernández-Chicarro: 213-225. Madrid. Ministerio de Cultura.

(1987): Tiro y las colonias fenicias de occidente. Barcelona, Ed. Bellaterra.

(1989): «La Mesa de Setefilla: la secuencia estratigráfica del corte 1», en M.E. Aubet (dtor.), Tartessos. Arqueología Protohistórica del Bajo Guadalquivir: 297-338. Sabadell, Ed. Ausa.

AUBET, M.E. y otros (1983): La Mesa de Setefilla. Lora del Río (Sevilla). Campaña de 1979 (Excavaciones Arqueológicas en España 122). Madrid, Ministerio de Cultura.

BELÉN, M. y ESCACENA, J.L. (e.p.a): «Las comunidades prerromanas de la Baja Andalucía», I Congreso de Paletnología de la Península Ibérica (Madrid, 1989).

(e.p.b): «Las necrópolis ibéricas de Andalucía occidental», Congreso Internacional de Arqueología Ibérica: Las Necrópolis (Madrid, 1991). 
(e.p.c): «Niebla (Huelva). Excavaciones junto a la Puerta de Sevilla (1978-1982). La cata 8», Huelva Arqueológica 12.

BELÉN, M. y FERNÁNDEZ-MIRANDA, M. (1978): «La Tiñosa (Lepe, Huelva)», Huelva Arqueológica IV: 197-297.

BELÉN, M. y PEREIRA, J. (1985): «Cerámicas a torno con decoración pintada en Andalucía», Huelva Arqueológica VII: 307-360.

BELÉN, M. y otros (1983): «Excavaciones en Niebla (Huelva)», XVI Congreso Nacional de Arqueología: 971-982. Zaragoza.

(1991): «El mundo funerario del Bronce Final en la fachada atlántica de la Península Ibérica. I. Análisis de la documentación», Trabajos de Prehistoria 48: 225-256.

BENDALA, M. (1990): «Tartessos hoy a la luz de los datos arqueológicos y literarios», en La Cultura Tartésica y Extremadura: 11-27. Mérida.

BERNIER, J. y FORTEA, J. (1963): «Niveles arqueológicos del Valle del Guadalquivir», Boletín de la Real Academia de Córdoba 85: 199-206.

BLANCO, A. (1979): Historia de Sevilla. I(1) La Ciudad Antigua (Desde la prehistoria a los visigodos). Sevilla, Universidad de Sevilla.

(1983): «Ategua», Noticiario Arqueológico Hispánico 15: 93-135.

BLANCO, A. y CORZO, R. (1981): «Der neue anthropoide Sarkophag von Cádiz», Madrider Mitteilungen 22: 236-243.

BLANCO, A. y ROTHENBERG, B. (1981): Exploración Arqueometalúrgica de Huelva. Barcelona, Ed. Labor.

BLANCO, A. y otros (1969): «Panorama tartésico en Andalucía oriental», Tartessos y sus problemas. $V$ S.I.P.P. (Jerez de la Frontera, 1968): 119-162. Barcelona. (1970): Excavaciones Arqueológicas en el Cerro Salomón (Riotinto, Huelva). Sevilla, Universidad.

BLANCO DE TORRECILLAS, C. (1959): «El tesoro del cortijo de «Evora» (Sanlúcar de Barrameda)», Archivo Español de Arqueología XXXII, 99 y 100: 50-57.

BLÁZQUEZ, J.M. y VALIENTE, J. (1981): Cástulo III (Excavaciones Arqueológicas en España 117). Madrid, Ministerio de Cultura.

BLÁZQUEZ, J.M. y otros (1971): «La factoría púnica en Aljaraque, provincia de Huelva», Noticiario Arqueológico Hispánico XIII-XIV: 304-331.

BUERO, M.S. y otros (1978): «Yacimiento del Bronce en Santa Eufemia», Archivo Hispalense, $2^{\mathrm{a}}$ época, LXI, $\mathbf{n}^{\circ}$ 186: 59-64.

CAMPOS, J.M. (1985): «El origen de Sevilla. El corte SI-85/6», Anuario Arqueológico de Andalucía/ 1985. II, Actividades Sistemáticas: 173-178.

CAMPOS, J.M. y otros (1988): Protohistoria de la Ciudad de Sevilla. El corte estratigráfico San Isidoro 85-6 (Monografías Arqueológicas de Andalucía 1). Sevilla, Consejería de Cultura de la Junta de Andalucía.

CARDENETE, R. y otros (1988a): «Excavaciones arqueológicas de urgencia en el solar de la C/ Higueral 2, Carmona (Sevilla)». Anuario Arqueológico de Andalucía / 1988. III, Actividades de Urgencia: 257263.

(1988b): «Excavaciones arqueológicas de urgencia en el solar de la C/ General Freire s/n. Sevilla», Anuario Arqueológico de Andalucía / 1988. III, Actividades de Urgencia: 271-278.

1989: «Excavaciones arqueológicas de urgencia en el solar de la calle Costanilla Torre del Oro sn. Carmona (Sevilla)», Anuario Arqueológico de Andalucía / 1989. III, Actividades de Urgencia: 563574. 
CARO, A. (1986-87): «Nabrissa (Lebrija, Sevilla). Los orígenes del núcleo urbano», Anales de la Universidad de Cádiz III-IV: 55-70.

(1989): Cerámica gris a torno tartesia. Cádiz, Universidad de Cádiz.

CARO, A. y otros (1986): «Informe sobre la prospección arqueológica con sondeo estratigráfico en el solar de la calle Alcazaba (Lebrija- Sevilla)». Anuario Arqueológico de Andalucía / 1986. II, Actividades Sistemáticas: 168-174.

CARRIAZO, J. de M (1970a): El tesoro y las primeras excavaciones en "El Carambolo» (Camas, Sevilla)» (Excavaciones Arqueológicas en España 68). Madrid, Ministerio de Educación y Ciencia. (1970b): El tesoro y las primeras excavaciones de Ebora (Sanlúcar de Barrameda) (Excavaciones Arqueológicas en España 69). Madrid, Ministerio de Educación y Ciencia.

(1973): Tartesos y El Carambolo. Madrid.

(1978): El Carambolo. Sevilla, Universidad de Sevilla.

CARRIAZO, J. de M. y RADDATZ, K. (1960): «Primicias de un corte estratigráfico en Carmona», Archivo Hispalense 103-104: 12-49.

COLLANTES DE TERAN, F. (1977): Contribución al estudio de la topografía sevillana en la Antigüedad y en la Edad Media. Sevilla, Patronato «José $\mathrm{M}^{\mathrm{a}}$ Quadrado» del C.S.I.C.-Monte de Piedad y Caja de Ahorros de Sevilla.

CORZO, R. (1991): Las Termas, la Ciudad y el Río de Sevilla en la Antigüedad. Excavaciones en la Calle Abades. Discurso de Ingreso en la Real Academia de Bellas Artes de Santa Isabel de Hungría. Sevilla, Ed. Real Maestranza de Caballería de Sevilla.

CUADRADO, E. (1962): «Cerámica astitana de barniz rojo», VII Congreso Nacionál de Arqueología: 385-408. Zaragoza.

(1969): «Origen y desarrollo de la cerámica de barniz rojo en el mundo tartésico», Tartessos y sus problemas. V S.I.P.P. (Jerez de la Frontera, 1968): 257-290. Barcelona.

CUNLIFFE, B.W. y FERNANDEZ CASTRO, M.C (1987): «Torre Paredones. (Castro del Río-Baena, Córdoba). Informe preliminar. Campaña de 1987: prospección arqueológica con sondeo estratigráfico», Anuario Arqueológico de Andalucía /1987. II, Actividades Sistemáticas: 193-199.

CHAVES, F. y DE LA BANDERA, M.L. (1984): «Avance sobre el yacimiento arqueológico de Montemolín (Marchena, Sevilla)», Papers in Iberian Archaeology (BAR International Series 193): 141-186. Oxford.

(1985): «Excavaciones en el yacimiento arqueológico de Montemolín (Marchena, Sevilla)», Anuario Arqueológico de Andalucía/ 1985. II, Actividades Sistemáticas: 369-375.

(1986): «Figürlich verzierte Keramik aus dem Guadalquivir-Gebiet. Die Funde von Montemolín (bei Marchena, Prov. Sevilla)», Madrider Mitteilungen 27: 117-150.

(1987): «Informe de la campaña de excavación de 1987: Montemolín (Marchena)», Anuario Arqueológico de Andalucía / 1987. II, Actividades Sistemáticas: 317-327.

(1991): «Aspectos de la urbanística en Andalucía occidental en los S. VII-VI a.C. a la luz del yacimiento de Montemolín (Marchena, Sevilla)», Atti del II Congresso Internazionale di Studi Fenici e Punici II: 691-714. Roma.

DE FRUTOS, G (1991): Cartago y la política colonial. Los casos norteafricano e hispano. Sevilla, Ed. Gráficas Sol.

DE FRUTOS, G. y otros (1988): «Las ánforas de la factoría prerromana de salazones de «Las Redes» (Puerto de Santa María, Cádiz)», $I^{\circ}$ Congreso Peninsular de Historia Antigua, vol. I: 295-306, Santiago de Compostela, Servicio de Publicaciones de la Universidad.

DE HOZ, J. (1989): «El desarrollo de la escritura y las lenguas de la zona meridional», en M. E. Aubet (dtor.), Tartessos. Arqueología Protohistórica del Bajo Guadalquivir: 523-587. Sabadell, Ed. Ausa. 
DE LA BANDERA, M.L. (1987): La joyería orientalizante e ibérica del s. VII al I a.C. (mitad sur peninsular). Sevilla. Ed. en microfichas.

DÍAZ DEL OLMO, F. (1989): «Paleogeografía tartésica», en M.E. Aubet (dtor.), Tartessos. Arqueología Protohistórica del bajo Guadalquivir: 13-23. Sabadell, Ed. Ausa.

DOMÍNGUEZ, C. y otros (1988): «Cerro de la Cabeza (Santiponce, Sevilla)», Noticiario Arqueológico Hispánico 30: 119-186.

ESCACENA, J.L. (1979-80): «Cerámica ibérica de Setefilla (Sevilla)», Pyrenae 15-16: 181-210. (1983): «Problemas en torno a los orígenes del urbanismo a orillas del Guadalquivir», Gades 11: 3983.

(1986): «OSSET IVLIA CONSTANTIA: San Juan de Aznalfarache (Sevilla)», Habis 17: 539-547. (1987a): «El poblamiento ibérico en el Bajo Guadalquivir», Iberos. Actas de las I Jornadas sobre el Mundo Ibérico / Jaén, 1985: 273-298. Jaén, Ayuntamiento de Jaén-Junta de Andalucía.

(1987b): Cerámicas a torno pintadas andaluzas de la segunda Edad del Hierro. Cádiz, Ed. en microfichas del Dpto. Arq. de la Universidad de Cádiz.

(1989): «Los Turdetanos o la recuperación de la identidad perdida», en M.E. Aubet (dtor.), Tartessos. Arqueología Protohistórica del Bajo Guadalquivir: 433-476. Sabadell, Ed. Ausa.

(1992): «Indicadores étnicos en la Andalucía prerromana», Spal 1.

(e.p.): «Reflexiones acerca del mundo funerario de la transición Calcolítico-Bronce en Andalucía occidental. A propósito del hallazgo de un enterramiento en pozo siliforme en Puebla del Río (Sevilla)», Homenaje al Prof. Pellicer. Tabona.

ESCACENA, J.L. y BELÉN, M. (1991): «Sobre la cronología del horizonte fundacional de los asentamientos tartésicos», Cuadernos del Suroeste 2: 9-42.

(e.p.): «Sobre las necrópolis turdetanas», Homenaje a F. Presedo. Sevilla.

ESTEVE, M. (1945): Excavaciones de Asta Regia (Mesas de Asta, Jerez). Campaña de 1942-43 (Acta Arqueológica Hispánica III). Madrid.

(1950): Excavaciones de Asta Regia (Mesas de Asta, Jerez). Campaña de 1945-46 (Informes y Memorias de la Comisaría General de Excavaciones Arqueológicas 22). Madrid.

(1962): Excavaciones de Asta Regia (Mesas de Asta, Jerez). Campañas de 1949-50 y de 1955-56 (Publicaciones del Centro de Estudios Históricos Jerezanos 19). Jerez de la Frontera.

(1969): «Asta Regia: una ciudad tartésica», Tartessos y sus problemas. V Symposium Internacional de Prehistoria Peninsular (Jerez de la Frontera, 1968): 111-118. Barcelona.

(1979): «Contribución al conocimiento de Asta Regia», Miscelánea Arqueológica Jerezana: 27-58. El mismo artículo en Actas y Memorias de la Sociedad Española de Antropología, Etnografía y Prehistoria XVI (1941): 386 ss.

FERNÁNDEZ GÓMEZ, F. y otros

(1979): «Excavaciones en «El Cerro Macareno». (Cortes E-F-G. Campaña 1974)», Noticiario Arqueológico Hispánico 7: 7-94.

FERNÁNDEZ JURADO, J. (1986): «Economía tartésica: minería y metalurgia», Huelva en su Historia. Miscelánea Histórica: 149-170. Sevilla, Servicio de Publicaciones del Colegio Universitario de La Rábida.

(1987a): «El poblamiento ibérico en Huelva», Iberos. Actas de las I Jornadas sobre el Mundo Ibérico / Jaén, 1985: 315-326. Jaén, Ayuntamiento de Jaén-Junta de Andalucía.

(1987b): «Tejada la Vieja: una ciudad protohistórica», Huelva Arqueológica IX.

(1988-89): «Tartessos y Huelva», Huelva Arqueológica X-XI.

(1991): «Ciudades y fortificaciones turdetanas», Simposi Internacional d'Arqueologia Ibèrica. 
Fortificacions. La Problemàtica de l'Ibèric Ple: (Segles IV-III a.C.). (Manresa, 1990): 55-66. Manresa, Centre d'Estudis del Bages- Societat Catalana d'Arqueologia.

FERNÁNDEZ JURADO, J. y RUIZ MATA, D. (1985): «La metalurgia de la plata en época tartésica en Huelva», Pyrenae 21: 23-42.

FERREIRO, M. (1981): «En torno a la posibilidad de establecer una estratigrafía teórica en un yacimiento arqueológico", $V^{a}$ Reunión del Grupo Español de Trabajo del Cuaternario. Actas y Guías de Excursiones: 189-198. Sevilla.

(1982): «Asta Regia según los geógrafos antiguos», Gades 9: 155-177.

(1985): «Aproximación al establecimiento de un modelo matemático en un yacimiento arqueológico», Gades 13: 61-68.

FLORIDO, C. (1984): «Anforas prerromanas sudibéricas», Habis 15: 419-436.

GARCÍA VARGAS, E. y otros (1989): «Estudios sobre cerámicas ibéricas andaluzas: Montemolín (Marchena, Sevilla)», Habis 20: 217-243.

GARCÍA Y BELLIDO, A. (1970): «Los hallazgos cerámicos del área del templo romano de Córdoba» Anejos de Archivo Español de Arqueología V.

GONZÁLEZ RODRIGUEZ, R. (1985): «Excavaciones de urgencia en el Cerro Naranja (Jerez de la Frontera, Cádiz), 1985», Anuario Arqueológico de Andalucía / 1985. II, Actividades de Urgencia: 90 96.

GONZÁLEZ WAGNER, C. (1983): «Aproximación al proceso histórico de Tartessos», Archivo Español de Arqueología 56: 3-35.

GONZÁLEZ WAGNER, C. y ALVAR, J (1989): «Fenicios en Occidente: la colonización agrícola», Rivista di Studi Fenici XVII, 1: 61-102.

HARDEN, D.B. (1937): «The pottery from the precinct of Tanit at Salambo, Carthague», Iraq IV, 1: 5989.

HARRIS, E.C. (1991): Principios de estratigrafía arqueológica. Barcelona, Ed. Crítica.

JUDICE, T. (1988): Social Complexity in Southwest Iberia 800-300 B.C. The Case of Tartessos (BAR International Series 439). Oxford.

KUKAHN, E. (1951): «El sarcófago sidonio de Cádiz», Archivo Español de Arqueología 24: 23-34.

KUKAHN, E. y BLANCO, A. (1959): «El tesoro de «El Carambolo»», Archivo Español de Arqueología XXXII, 99 y 100: 38-49.

LADRÓN DE GUEVARA, I. y otros (1992): «Materiales inéditos de Setefilla (Lora del Río, Sevilla)», Spal 1: 293-312.

LÓPEZ PALOMO, L.A. (1981): «Alhonoz (Excavaciones de 1973 a 1978)», Noticiario Arqueológico Hispánico 11: 33-188.

(1987): «Prospección arqueológica con sondeo estratigráfico en el yacimiento de Colina del Castillo de Monturque, en el término municipal de Monturque, provincia de Córdoba», Anuario Arqueológico de Andalucía / 1987. II, Actividades Sistemáticas: 180-192.

LUZÓN, J.M. y RUIZ MATA, D. (1973): Las Raíces de Córdoba. Estratigrafía en la Colina de los Quemados. Diputación Provincial de Córdoba. Córdoba.

MALUQUER, J. (1958): «Nuevos hallazgos en el área tartésica», Zephyrus IX: 201- 219.

(1968): Epigrafia prelatina de la Península Ibérica. Barcelona.

MANCEBO, J. e.p.: «La cerámica de barniz rojo de Montemolín (Marchena, Sevilla)», Zephyrus.

MARCOS, A. (1976-78): «Aportaciones a la localización y conocimiento de la Corduba prerromana», Ampurias 38-40: 415-422.

MARTÍN-BUENO, M. (1983): «Primeros resultados de las excavaciones de Ategua (Córdoba)», Momenaje al Prof. Martín Almagro Basch III: 227- 233. Madrid, Ministerio de Cultura. 
MARTíN DE LA CRUZ, J.C. (1976): «El corte F del Cerro Macareno, La Rinconada (Sevilla)», Cuadernos de Prehistoria y Arqueología (U.A.M.) 3: 9-31.

(1985): «La campaña de 1985 en el Llanete de los Moros, Palomarejo (Montoro, Córdoba)», Anuario Arqueológico de Andalucía/ 1985. II, Actividades Sistemáticas: 313-318.

(1987): El Lanete de los Moros, Montoro, Córdoba (Excavaciones Arqueológicas en España 151). Madrid, Ministerio de Cultura.

MAYORAL, E.J. (1989): «Geología de la Depresión Inferior del Guadalquivir», en El Cuaternario en Andalucía Occidental (AEQUA Monografías 1): 7-20. Sevilla.

MENDOZA, A. y otros (1981): «Cerro de los Infantes (Pinos Puente, Provinz Granada). Ein Beitrag zur Bronze- und Eisenzeit in Oberandalusien», Madrider Mitteilungen 22: 171-210.

MURILLO, J.F (1989): «Cerámicas tartésicas con decoración orientalizante», Cuadernos de Prehistoria y Arqueología (U.A.M.) 16: 149-167.

(1991): Análisis del poblamiento durante el Bronce Final y el Periodo Orientalizante en la cuenca media del Guadalquivir. Universidad de Córdoba. Tesis doctoral inédita.

MURILLO, J.F. y otros (1989): «Aproximación al estudio del poblamiento protohistórico en el sureste de Córdoba: unidades políticas, control del territorio y fronteras», Fronteras. Arqueología Espacial 13 (Teruel, 1989): 151-172. Teruel.

PASTOR, M. y otros (1981): «Cerro de la Mora (Moraleda de Zafayona. Granada)», Noticiario Arqueológico Hispánico 12: 135-158.

PELLICER, M. (1963): «Ein altpunisches Gräberfeld bei Almuñécar (Prov. Granada)», Madrider Mitteilungen 4: 9-38.

(1969): «Las primeras cerámicas a torno pintadas andaluzas y sus problemas», Tartessos y sus problemas. V Symposium Internacional de Prehistoria Peninsular (Jerez de la Frontera, 1968): 291310. Barcelona.

(1976-78): «Problemática general de los inicios de la iberización en Andalucía occidental», Ampurias 38-40: 3-22.

(1978): «Tipología y cronología de las ánforas prerromanas del Guadalquivir según el Cerro Macareno (Sevilla)», Habis 9: 365-400.

(1982): «Las cerámicas del mundo fenicio en el Bajo Guadalquivir: evolución y cronología según el Cerro Macareno (Sevilla)», Phönizier im Westen (Madrider Beiträge 8): 371-406.

(1983): «El yacimiento protohistórico de Quebrantahuesos (Riotinto, Huelva)», Noticiario Arqueológico Hispánico 15: 59-91.

(1987-88): «Las cerámicas a mano del Bronce Reciente y del Orientalizante en Andalucía occidental», Habis 18-19: 461- 483.

PELLICER, M. y AMORES, F (1985): «Protohistoria de Carmona. Los cortes estratigráficos CA- 80/A y CA-80/B», Noticiario Arqueológico Hispánico 22: 56- 189.

PELLICER, M. y HURTADO, V. (1980): El poblado metalúrgico de Chinflón. (Zalamea la Real, Huelva). Sevilla, Publicaciones del Dpto. de Prehistoria y Arqueología.

(1986): «Excavaciones en la Mesa de El Gandul (Alcalá de Guadaira, Sevilla)», Anuario Arqueológico de Andalucía / 1986. II, Actividades Sistemáticas: 338-341.

PELLICER, M. y SCHÜLE, W. (1966): El Cerro del Real (Galera, Granada). El corte estratigráfico IX (Excavaciones Arqueológicas en España 52). Madrid, Ministerio de Cultura.

PELLICER, M. y otros (1983): El Cerro Macareno (Excavaciones Arqueológicas en España 124). Madrid, Ministerio de Cultura.

PEMÁN, C. (1942): Memoria sobre la situación arqueológica de la provincia de Cádizen 1940 (Informes y Memorias de la Comisaría General de Excavaciones Arqueológicas 1). Madrid. 
PERDIGUERO, M. (1986): «Excavaciones arqueológicas efectuadas el Cauche el Viejo (Antequera, Málaga)», Anuario Arqueológico de Andalucía / 1986. II, Actividades Sistemáticas: 408-421. (1987): «Informe preliminar correspondiente a las excavaciones arqueológicas sistemáticas efectuadas en Cauche el Viejo, Aratispi (Antequera, Málaga). Segunda campaña 1987», Anuario Arqueológico de Andalucía / 1987. II, Actividades Sistemáticas: 301-309.

RAMOS, J. y otros (1989): Arqueología en Jerez. Primera aproximación al estudio de las industrias líticas de su Prehistoria reciente. Jerez de la Frontera, Ed. Biblioteca de Urbanismo y Cultura.

REMESAL, J. (1975): «Cerámicas orientalizantes andaluzas», Archivo Español de Arqueología 48, nº 131 y $132: 3-21$.

ROOS, A.M. (1982): «Acerca de la antigua cerámica gris a torno en la Península Ibérica», Ampurias 44: 43-70.

RUBIO, J.M. (1989): «Elementos y organización del medio físico», en El Cuaternario en Andalucía Occidental (AEQUA Monografías 1): 3-6. Sevilla.

RUIZ DELGADO, M.M (1985): Carta arqueológica de la campiña sevillana. Zona sureste I. Sevilla. Universidad de Sevilla.

RUIZ MATA, D. (1979): «El Bronce Final -fase inicial- en Andalucía occidental. Ensayo de definición de sus cerámicas», Archivo Español de Arqueología 52: 3-19.

(1981): «El poblado metalúrgico de época tartésica de San Bartolomé (Almonte, Huelva)», Madrider Mitteilungen 22: 150-170.

(1986a): «Las cerámicas fenicias del Castillo de Doña Blanca (Puerto de Santa María, Cádiz)», en G. del Olmo y M.E. Aubet (dtres.), Los Fenicios en la Península Ibérica, vol. I: 241-263. Sabadell, Ed. Ausa.

(1986b): «Informe sobre las excavaciones sistemáticas realizadas en el yacimiento del Castillo de Doña Blanca (Puerto de Santa María, Cádiz)», Anuario Arqueológico de Andalucía / 1986. II, Actividades Sistemáticas: 360-365.

(1986c): «Aportación al análisis de los inicios de la presencia fenicia en Andalucía sudoccidental, según las excavaciones del Cabezo de San Pedro (Huelva), S. Bartolomé (Almonte, Huelva), Castillo de Doña Blanca (Puerto de Santa María, Cádiz) y El Carambolo (Camas, Sevilla)», Homenaje a Luis Siret (1934-1984): 537-556. Sevilla, Consejería de Cultura de la Junta de Andalucía.

(1987a): «La formación de la cultura turdetana en la Bahía de Cádiz a través del Castillo de Doña Blanca», Iberos. Actas de las I Jornadas sobre el Mundo Ibérico / Jaén, 1985: 299-314. Jaén, Ayuntamiento de Jaén-Junta de Andalucía.

(1987b): «Informe sobre la campaña de excavaciones de 1987 realizada en el Castillo de Doña Blanca

(El Puerto de Santa María, Cádiz)», Anuario Arqueológico de Andalucía / 1987. II, Actividades Sistemáticas: $380-384$.

RUIZ MATA, D. y FERNANDEZ JURADO, J. 1986: «El yacimiento metalúrgico de época tartésica de San Bartolomé de Almonte (Huelva)», Huelva Arqueológica VIII.

RUIZ RODRÍGUEZ, A. y MOLINOS, M. (1986): «Excavación arqueológica sistemática en Puente Tablas (Jaén)», Anuario Arqueológico de Andalucía / 1986. II, Actividades Sistemáticas: 401-407.

RUIZ RODRÍGUEZ, A. y otro (1991): "Fortificaciones ibéricas en la Alta Andalucía», Simposi Internacional d'Arqueologia Ibèrica. Fortificacions. La Problemàtica de l'Ibèric Ple: (Segles IV-III a.C.). (Manresa, 1990): 109-126. Manresa. Centre d'Estudis del Bages-Societat Catalanad'Arqueologia. SALLES, J.-F.

(1980): La nécropole "K» de Biblos. Recherche sur les grandes civilisations, mémoire $\mathrm{n}^{\circ} 2$. Maison de l'Orient. S.I., Editions ADPF. 
SCHUBART, H. (1971): «Acerca de la cerámica del Bronce Tardío en el Sur y Oeste peninsular», Trabajos de Prehistoria 28: 153-182.

SCHUBART, H. y ARTEAGA, O. (1986): «El mundo de las colonias fenicias occidentales», Homenaje a Luis Siret (1934-1984): 499-525. Sevilla, Consejería de Cultura de la Junta de Andalucía.

SCHUBART, H. y otros (1969): Toscanos: la factoría paleopúnica en la desembocadura del río Vélez. (Excavaciones Arqueológicas en España 66). Madrid, Ministerio de Cultura.

SOTOMAYOR, M. y otros (1981): «Los alfares romanos de Los Villares de Andújar (Jaén, campaña 1978-1979)», Noticiario Arqueológico Hispánico 11: 307-368.

TEJERA, A. (1985): «Excavaciones Arqueológicas en el Huerto Pimentel (Lebrija, Sevilla)», Noticiario Arqueológico Hispánico 26: 88-116.

VENTURA, J.J. (1985): «La cerámica campaniense de la «Cuesta del Rosario» (Sevilla)», Archivo Español de Arqueología 58, 151-152: 41- 62.

VERA, M. (1987): «Aportación al conocimiento de la Sevilla antigua. Revisión de la excavación de Cuesta del Rosario», Archivo Hispalense, $2^{\mathrm{a}}$ época, LXX, $\mathrm{n}^{\circ}$ 215: 37-60.

VILLARONGA, L. (1973): Las monedas hispano-cartaginesas. Barcelona. 


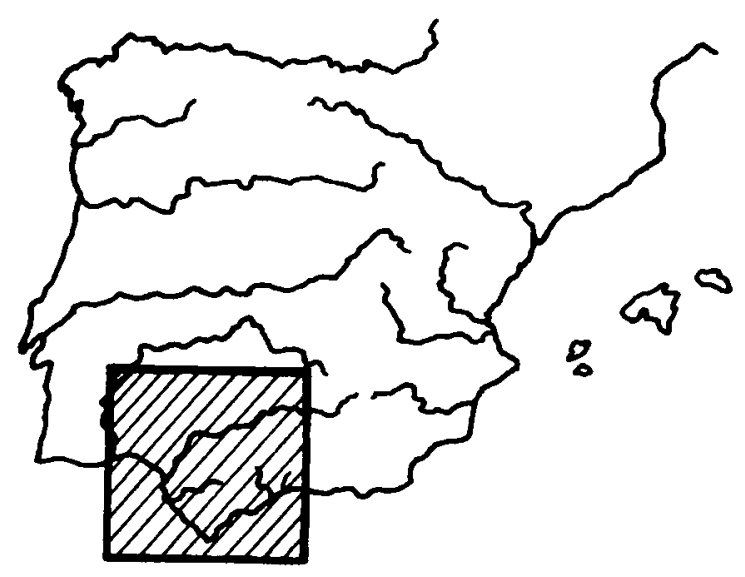

$\mathcal{L}$

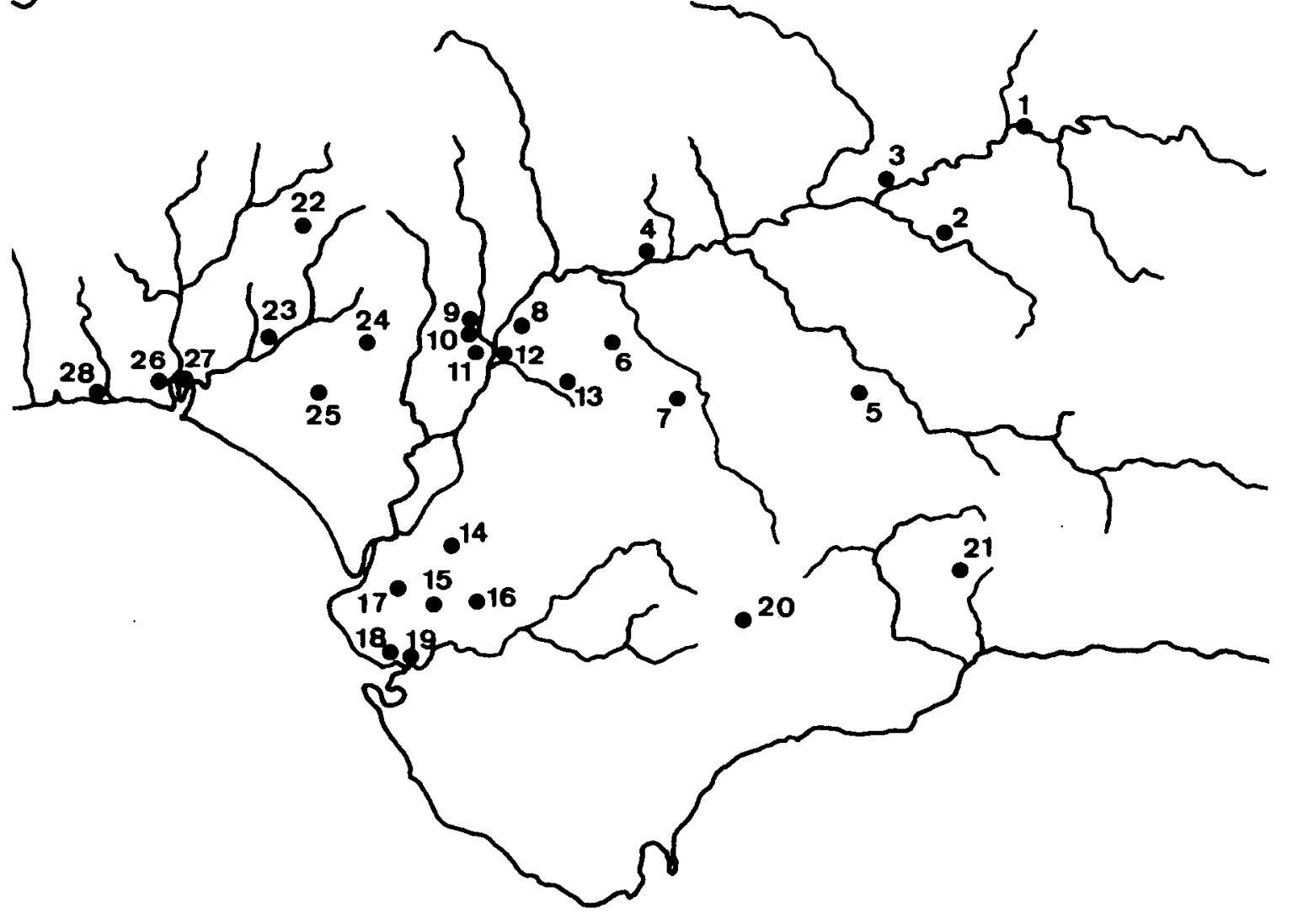

MAPA GENERAL DE YACIMIENTOS 